1973

\title{
MODULATION OF CORTICAL AND PYRAMIDAL TRACT INDUCED MOTOR RESPONSES BY ELECTRICAL STIMULATION OF THE BASAL GANGLIA
}

Roberta Ann Newton

Follow this and additional works at: https://scholarscompass.vcu.edu/etd

Part of the Physiology Commons

(C) The Author

\section{Downloaded from}

https://scholarscompass.vcu.edu/etd/5220

This Dissertation is brought to you for free and open access by the Graduate School at VCU Scholars Compass. It has been accepted for inclusion in Theses and Dissertations by an authorized administrator of VCU Scholars Compass. For more information, please contact libcompass@vcu.edu. 


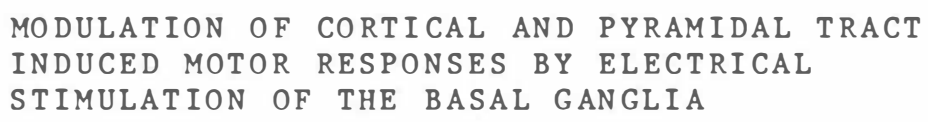

b y

Roberta Ann Newton

B.S., Mary Washington College, 1969

Thes is

submitted in partial fulfillment of the requirements for the Degree of Doctor of Philosophy in the Department of Physiology at the Medical College of Virginia Health Sciences Division, Virginia Commonwealth University Richmond, Virginia October, 1973 
This thesis by Roberta Ann Newton is accepted in its present form as satisfying the thesis requirement for the degree of Doctor of Philosophy.

Date:

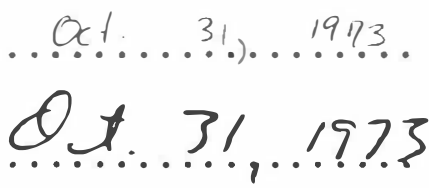

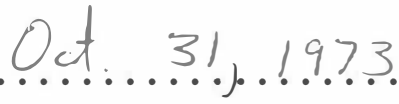

od 31.1973

Oct 31, 1973
Approved:
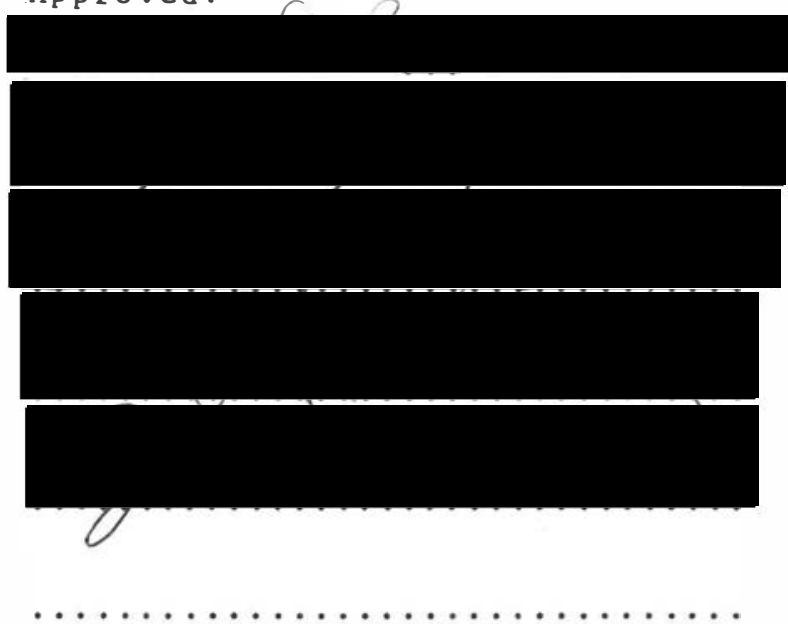

AP P ROVED :

Dean of the School of Basic Sciences and Graduate Studies 


\section{ACKNOWLEDGMENTS}

I would like to express appreciation to my advisors, Dr. Donald D. Price and Dr. Alfred J. Szumskifor their interest and encouragment in this profect. Thanks also goes to Mr. James E. Forbes, Dr. Dorothy D. Greenhouse and Ms. Carolyn S. Meador for thelr assistance in all portions of the profect; and to Ms. Sandra J. orton for the artwork. Special thanks 1 s expressed to Dr. Anna S. Hoye, Ms. Mary Jo Mays and my family for their encouragment and moral support. 
TABLE OF CONTENTS

PAGE

Introduction

Review of the Literature

A. Anatomy of the Basal Ganglia

1. Cytoarchitecture of the Striatum and Globus Pallidus

2. Afferent Fiber Connections of the Striatum

3. Efferent Fiber Projections of the

4. Efferent Fiber Projections of the Globus Pallidus

B. Ablation Studies Involving the Basal Gang 11 a

C. Electrical Stimulation of the Basal Gangl1a

D. Intracellular and Unit Activity of the Caudate Nucleus and Lentiform Nucleus

1. Activity of Lenticular Neurons during Movement

Methods

A. Anesthetized Preparation 39

1. Surgical Procedures 40

a. Exposure of the Bulbar Pyramids 40

b. Denervation of the Hind Limb and Dissection of the Anterior Tibialis Muscle

c. Framing the Cat

d. Laminectomy and Preparation of the Dorsal Root

e. Exposure of the Cortex

2. Recording Procedure

3. Experimental Format

4. Data Analysis 
B . Unanesthetized Preparation

3. Data Analysis

C. Histology

Results

A. Anesthetized Preparation

1. Ia Afferent Dorsal Root Activity

2. Caudate Nucleus Modulation of Cortical and Pyramidal Tract Induced Activity

3. Globus Pallidus Modulation of Cortical and Pyramidal Tract Activity

4. Internal Capsule

5. Decorticate Preparation

B. Unanesthetized Preparation

1. Modulation of Evoked D-I Responses by Stimulation of the Caudate Nucleus

2. Globus Pallidus Modulation of D-I Responses

Discussion

A. Anesthetized Preparation

1. Supraspinal Regulation of Ia Afferent Activity

2. Facilitatory and Inhibitory Modulating

4. Facilitatory Modulation of the Globus Pallidus

5. Current Spread

B. Proposal of Hypothesis Defining Inhibitory Influences

C. Unanesthetized Preparation 
v11

D. Synthes1s: Regulatory Influences of the Basal Ganglia

114

E. Central Regulation of Movement

S ummary

124

References

127 


\section{LIST OF FIGURES}

Figure 1. Fiber Profections of the Basal Ganglia and Related Structures

Figure 2. Diagram of the Experimental

Arrangement of Stimulating and

Recording Electrodes in the

Anesthetized Preparation

Figure 3. Diagram of the Experimental

Arrangement of Stimulating and

Recording Electrodes in the

Unanesthetized Preparation

Figure 4. Caudate Nucleus Modulation of a

Cortically Induced Flexor Response:

Inhibition

Figure 5. Caudate Nucleus Modulation of a

Cortically Induced Flexor Response:

Facilitation

Figure 6. Loci within the Caudate Nucleus which

Altered Cortically Induced Motor

Activity in the Anesthetized

Preparation

Figure 7. Caudate Nucleus Modulation of a

Pyramidal Tract Induced Flexor

Response: Facilitation

Figure 8. Loci within the Caudate Nucleus which Altered Pyramidal Tract Induced Motor Activity in the Anesthetized

Preparation

Figure 9. Globus Pallidus Modulation of a

Cortically Induced Flexor Response

Figure 10. Globus Pallidus Modulation of a

Pyramidal Tract Induced Flexor Response

Figure 11. Loci within the Globus Pallidus which Altered Cortically Induced and Pyramidal Tract Induced Motor Responses 
Figure 12. Caudate Nucleus Modulation of a Pyramidal Tract Induced Flexor Response in the Decorticate Cat

Figure 13. Loci within the Caudate Nucleus which Altered Pyramidal Tract Responses in the Decorticate Preparation

Figure 14. Changes in Amplitude of the Direct and Indirect Responses Recorded in the Pyramidal Tract

Figure 15. Variation in Direct and Indirect Responses Recorded in the Pyramidal Tract due to Increasing Intensities of Cortical Stimulation

Figure 16. Modulation of Cortically Induced Direct and Indirect Responses by Caudate Stimulation: Inhibition

Figure 17. Modulation of Cortically Induced Direct and Indirect Responses by Caudate Nucleus Stimulation:

Facilitation

Figure 18. Loci within the Caudate Nucleus which Altered Cortical Induced D-I Responses in the Unanesthetized Preparation

Figure 19. Synthesis: Regulatory Influences of the Basal Ganglia 


\section{INTRODUCTION}

Since the early $1800^{\prime} \mathrm{s}$, the basal ganglia have been recognized as an extrapyramidal subcortical motor area. Much of the knowledge of basal ganglia involvement in movement has been obtained through clinical symptomology. Consideration of the basal ganglia as a pure inhibitory influence upon motor regulation was a concept generated by early researchers $(24,57,58)$. In spite of the fact that the basal ganglia was considered an inhibitory center, it was known that the basal ganglia produced fore $11 \mathrm{mb}$ flexion or contraversive head turning. At the present, both facilitatory and inhibitory Influences upon motor activity have been demonstrated (50). Physlological mechanisms underlying basal ganglia involvement in movement have been difficult to assess due to the fact that: (1) electrical stimulation and discrete surgical lesions within this subcortical area fall to produce as significant a change in locomotor activity as that observed In dysfunction; and (2) the basal ganglia are many synapses removed from sensory input and from lower motoneurons. Varlous approaches have been utilized to elucidate motor influences of the basal gangl1a. These Include: (1) ablation of one or more basal ganglia structures;

(2) electrical stimulation of basal ganglia structures;

(3) modulation of pre-existing motor activity by electrical stimulation of regions within the basal ganglia; (4) more recently, unit 
recording in basal ganglia structures in chronic preparations during a task related movement.

Early investigators postulated that the basal ganglia exerted a steadying influence upon the pyramidal tract (86). Modulation of the gamma motoneuronal system by subcortical structures pertained to the alteration of background activity on a spinal level. Since some basal ganglia dysfunctions result in the alteration of tone as well as hyperactivity, one would suspect that they modulate the gamma motoneuronal system. Granit and Kaada (26) Investigated basal ganglia Influences upon gamma activity but did not determine the pathway by which these influences were mediated. They did not Investigate basal ganglia modulation of cortically Induced increase in gamma discharge. Thus, the question was ralsed as to whether or not the basal ganglia actually modulated cortically induced increases in gammactivity.

Two general mechanisms based on anatomical studies are possible for the modulation of motor activity by the basal gangl1a. These mechanisms are: (1) modulation of the output of cortical neurons that exert motor influences and (2) modulation of subcortical neurons that exert motor influences. The former mechanism would occur via a well defined pathway from basal ganglia structures via the thalamus to the cortex (See Literature Review). Modulation could also occur via basal ganglia profections to subcortical areas which in turn profect to the spinal level. Differentiation between 
these two mechanisms was accomplished in the present study by two experimental approaches. The first was an investigation of basal ganglia modulation of flexor responses of the anterior tiblalis muscle eliclted by electrical stimulation of the sensorimotor cortex and pyramidal tract. These investigations were carried out in intact and in decorticate cats. The anterior tiblalis muscle is activated during the first phase, the flexion phase of movement (17). Therefore, this muscle was chosen for this study since a characteristic of some basal ganglia dysfunctions involves a slow onset or initiation of movement.

The second approach was an analysis of modulation of cortically induced pyramidal tract responses by conditioning shock trains delivered to various locl within the basal gangl1a. Both approaches were designed to determine whether Inhibitory and facilitatory motor influences of the basal ganglia occurred at a cortical or subcortical level. A major hypothesis to be tested was whether facilitatory and inhibitory regions existed within the caudate nucleus and more specifically, whether the rostral region of the caudate nucleus was inhibitory and the caudal region facilitatory as proposed by Liles and Davis (50). 


\section{REVIEW OF THE LITERATURE}

Controversy concerning the functional role of the basal ganglia has evolved since Willis in 1667 postulated the corpus striatum as an integrator between the cortex and medulla oblongata. Not only has the integrator role been disputed, but also whether or not the basal ganglia influenced locomotor activity. Magendie (60) postulated that the corpus striatum controlled backward movement, whereas forward propulsion was under the control of the cerebellum. In 1867 , Ferrier (60) described the relation of the corpus striatum with the cortex in terms of motor integration. During this perlod of time, the corpus striatum was considered a motor organ or a relay center between the cortex and spinal level from which arose fiber tracts that decussated in the medulla oblongata. This concept, then, incorporated the 1dea that the origin of the pyramidal tract was the corpus striatum. Wilson (86) through histological techniques and electrical stimulation obtained no positive results regarding the possibility of basal ganglia regulation of cortically induced motor activity. By analyzing the current anatomical and physlological evidence he concluded that: (1) the corpus striatum was not dependent upon the cortex; (2) the caudate nucleus and putamen had connections between themselves; and (3) both had fiber connections with the globus pallidus. The basal ganglia were regarded as a motor center that exerted 
a steadying Influence upon the pyramidal tract. Major input flbers to this center were derived from the thalamus and the major efferent fibers were channeled in a caudal direction to the spinal level via a rubrospinal projection. Removal of this influence, thereby removing a steadying influence upon the pyramidal tract, would result in tremor. Wilson's concept was replaced by a proposal of Dusser de Barenne and McCulloch (16) which Implicated the basal ganglia in a suppressor circult: area $4 \mathrm{~s}$ of the cerebral cortex-caudate nucleus-globus pallidus-thalamus-area 4 of the cerebral cortex. Therefore, the basal ganglia and cerebral cortex were once again considered functionally dependent. Bucy, 1932 (9), organized clinical, anatomical, and physlological research to describe chorea and athetosis, both attributed to dysfunction of the basal ganglia. This pathway, as described below, also considered the basal ganglia and cortex functionally dependent. A postulated pathway independent from the pyramidal tract which principally arose from area 6 was termed the parapyramidal tract. According to Bucy, the parapyramidal tract was composed of those fibers excluding the pyramidal tract fibers that arose in areas 4 and 6 and projected to subcortical structures other than the basal ganglia. These subcortical areas projected to the spinal leve1. The proposed mechanism for athetosis involved a cortical-cortical loop in which fibers that arose from the suppressor areas $8 \mathrm{~s}$ and $4 \mathrm{~s}$ (8s - anterior to area 6 ; 
$4 \mathrm{~s}$ - between areas 4 and 6) projected through a proposed pathway to the caudate nucleus. Flbers from the caudate nucleus passed to the globus pallidus, which in turn projected to areas 4 and 6 . This proposed loop, originating in the suppressor areas of the cortex would suppress activity In cortical motor areas 4 and 6 . Hence, interruption of the pathway would account for involuntary movements and hyperactivity. Ablation of area 4 disrupted the final pathway from the cortex via subcortical structures to the spinal level and thereby would provide a surgical method to decrease hyperactivity due to basal ganglia dysfunction. A more current analysis of the flber connections of the basal gangl1a w111 be described below.

During the development of the 1dea that the basal ganglia was a motor system also evolved the concept of the basal ganglia as an extrapyramidal motor system. The term, extrapyramidal, designated corticospinal projections excluding the pyramidal tract. Wilson employed the term when referring to basal ganglia dysfunctions. As the concept evolved, the terms pyramidal system and voluntary movement became analogous, whereas the extrapyramidal system was concerned with background or steadying influences upon motor activity. Thus pyramidal and extrapyramidal appeared to denote two distinct and separate systems. As a result, the terminology became misleading. Therefore, the term, extrapyramida1, is not employed in the present study. 
A. Anatomy of the Basal Ganglia

Located deep within the cerebral hemispheres, the basal ganglia form a conspicuous part of the forebrain. The putamen and caudate nucleus, derived from the telencephalon, are phylogenetically newer than the globus pallidus. Collectively these two structures, putamen and caudate nucleus, are termed striatum, a descriptive term characterizing the myelinated fibers traversing these structures, thereby producing a striated appearance. The putamen and globus pallidus are collectively termed lentiform nucleus. The cytoarchitecture and anatomical connections of these structures will be discussed so that physiological results to be described can be more adequately interpreted. Figure 1 represents major fiber connections of the basal ganglia and related fiber pathways described below.

1. Cytoarchitecture of the Striatum and Globus Pallidus

The putamen and caudate nucleus have similar cytoarchitecture. Early anatomical studies employing light microscopy and Nissl stain described the caudate nucleus as a structure containing small, densely packed cells. Extensive light and electron microscopy pertaining to the cytology of the caudate nucleus have been conducted by kemp and Powel1 (38). A major characteristic of the caudate nucleus is its homogeneous structure. Approximately ninety-six percent of the cell population is composed of one cell type which is characterized by a soma diameter 
Figure 1 Fiber Projections of the Basal Ganglia and Related Structures

A. Extrinsic fiber profections to the basal ganglia.

B. Efferent fiber projections of the basal ganglia.

C. Related fiber connections.

Abbreviations are as follows:

CL - centralis lateralis

CM - centrum medianum

Cd - caudate nucleus

GP - external segment of the globus pallidus

GP $P_{1}$ - Internal segment of the globus pallidus

$\mathrm{H}^{1}$ - fleld of Forel

Put - putamen

RF - reticular formation

SN - substantia nigra

STh - subthalamic nucleus

Th - thalamus 


$$
\text { ty }
$$




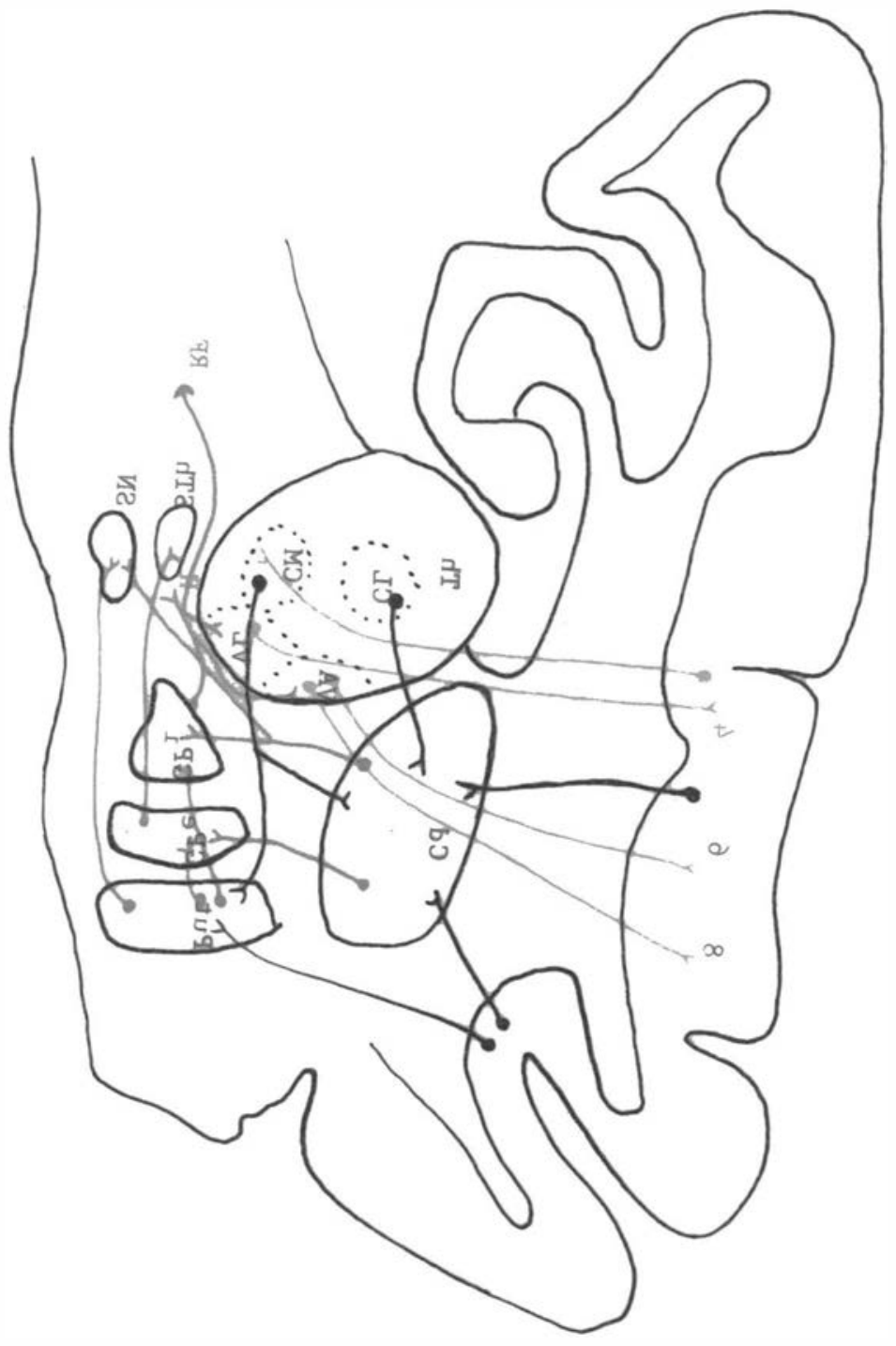


between $12 \mu m$ and $18 \mu m$ and a large number of dendritic spines. At locations where the heaviest concentrations of spines occur, they are difficult to differentiate with the ald of light microscopy. Five cell types, differing in soma size and density of dendritic spines, comprise the remaining four per cent of the total cell population. Both myelinated and unmyelinated axons have been described for the striatum. A characteristic of the caudate nucleus is a dense axonal plexus consisting of collaterals from the short axons of the most common cell types as well as extrinsic axons. A striking feature is that axons of the plexus cross dendrites rather than being organized in a parallel arrangement. Many of these axons form en passant contacts with dendrites, a characteristic ind Icative of widespread influence (42).

In primates the globus pallidus is composed of two segments, the internal segment and the external segment. The volume of the external segment of the globus pallidus represents sixty per cent of the total pallidal volume (29). In carnivores the internal segment of the globus pallidus is represented by the entopenduncular nucleus. Morgan (60) and Nauta and Mehler (62) have conflrmed that the ultrastructure and fiber connections of the entopenduncular nucleus in the cat are similar to those of the internal segment of the globus pallidus in the monkey. Cells within the external pallidum are greater in number and smaller in size than those of the internal pallidum. The multipolar 
cells of the internal pallidal segment have a fusiform shape and may be as large as 40 to $50 \mu \mathrm{m}$ in diameter. Axons tend to be more heavily myelinated and larger in diameter than those of the caudate nucleus or putamen. 2. Afferent Fiber Connections of the Striatum Fiber connections of the basal ganglia have been a subject of much controversy due to limitations in a suitable histological staining procedure for fine degenerating axons and in lesioning a subcortical area without producing secondary necrosis in surrounding tissue. Afferent fiber connections to the striatum arise from two major sources, the cortex and thalamic intralaminar nuclei, and a minor projection originates in the midbrain. An extensive, well organized projection from the entire neocortex projects in an essentially topographical manner to all parts of the caudate nucleus and putamen ( 85 ). The heaviest fiber concentration originates in motor and somatosensory cortical regions, areas which receive proprioceptive and somatosensory input. Input to the corpus striatum from the visual cortex is small. Area 5 and the supplementary motor area profect bilaterally to the corpus striatum. This bilateral projection tends to be greater in nonprimates. On the other hand, in primates the frontal cortex tends to project to the rostroventral region of the caudate nucleus, whereas, the sensorimotor cortex predominately profects to the putamen, but overlap of fiber projections to both structures 
is evident. Although a topographical arrangement is evident, considerable overlap and therefore convergence of afferent fibers from the cortex has been reported. This concept differs from Dusser de Barenne's concept of a nontopographical cortical projection in which suppressor bands project to the caudate nucleus and areas 4 and 6 project to the putamen.

Intralaminar thalamic nuclei, centralis lateralis and parafascicularis project to the caudate nucleus, whereas, the centrum medianum projects predominately to the putamen (4). The centrum medianum also projects to the caudate nucleus. These fiber projections are represented in Figure 1A. These thalamic nuclei, in turn receive projections from cortical areas, thereby forming a complex loop: cerebral cortex-thalamic nuclei-basal ganglia-thalamus-cerebral cortex.

The substantia nigra and a region adjacent to the red nucleus represent the origin of a third tragectory to the striatum. Controversy pertaining to the origin of these axons is due to the fact that electrolytic damage within the nigral area results in vascular damage and therefore secondary necrosis in neighboring areas. Existance for the substantia nigra projection to the caudate nucleus has been substantiated by the Falck and Hillarp (20) histochemical technique for the detection of dopaminergic fibers. Input to the caudate nucleus from the major afferent sources has been further supported by recording intracellular and unit 
activity within the caudate nucleus evoked by stimulation of extrinsic sources (See below).

3. Efferent Fiber Projections of the Striatum

Literature pertaining to the fiber connections and even to the polarity of fiber connections of the caudate nucleus represent a confusing picture. Efferent fibers from the corpus striatum, which are more heavily myelinated than the extrinsic afferent axons, terminate in the globus pallidus and In the substantia nigra. Wilson's classic March 1 experiments first described the fine radiating striatal profections. Vonelda (83) and Szabo (80) have presented a topographical representation of these efferent fiber connections in the monkey, and cat and money, respectively. Efferent fiber profections of the striatum are represented In Figure $1 \mathrm{~B}$.

Fibers from the medial aspect of the head of the caudate nucleus profect mainly to the internal segment of the globus pallidus. These fibers course in the ventrolateral aspect of the internal capsule and a portion of the bundle terminates In the dorsomedial aspect of the Internal pallidal segment. The remalnder of the flber bundle traverses in a ventromedial and caudal diection and terminates in the medial aspect of the substantia nigra. The middle portion of the head of the caudate nucleus gives rise to a fiber trafectory that traverses the ventrolateral portion of the internal capsule and enters the medial aspect of the external pallidal segment 
in a fan-like manner. A portion of these fibers project in a diffuse pattern through the external segment to terminate in the internal pallidal segment. The remainder of the fibers, still present in the internal capsule, penetrates the lateral and ventral aspect of the substantia nigra and terminates in the lateral one third of this structure. Fibers from the lateral portion of the head of the caudate nucleus traverse the internal capsule in a ventrolateral and caudal direction and penetrate the laterodorsal pole of the external segment of the globus pallidus. Over half of the bundle terminates in the dorsomedial one half to two thirds of the external pallidal segment. The remainder of the fiber bundle enters the internal pallidal segment and terminates in its dorsomedial aspect. A very few fibers course the internal capsule and terminate in the anterior portion of the substantia nigra. As is evident from the above description, efferent fibers from the head of the caudate nucleus are organized in a mediolateral pattern in both the globus pallidus and substantia nigra.

Szabo also examined efferent fiber projections from the body and tail of the caudate nucleus $(78,79)$. Fibers from the body of the caudate nucleus course in the internal capsule along the medial zone of the globus pallidus and putamen. Some fibers even traverse through the medial region of the putamen. Fiber projections from the lateral and medial region of the body of the caudate nucleus project 
predominately to the external and internal segments of the globus pallidus. This topographical arrangement is not strict and overlap from the caudate nucleus to both segments of the globus pallidus occurs. Some fibers remain in the internal capsule, traverse in a ventrolateral direction, course through the cerebral peduncle and terminate predominately in the lateral and ventral regions of the substantia nigra. Efferent fiber projections from the tail of the caudate nucleus course along the ventral border of the globus pallidus toward the cerebral peduncle, then course in a ventromedial-caudal direction and terminate in the pars reticulata of the substantia nigra. These fibers contribute to the "comb system". The "comb system" consists of those fibers that perforate the cerebral peduncle.

Early researchers postulated that the putamen profected only to the globus pallidus. However, fiber projections from the putamen to both the globus pallidus and the substantia nigra have been confirmed (61). Efferent fibers from the putamen project in an organized manner, a dorsoventral and mediolateral arrangement, to the ventrolateral region of both segments of the globus pallidus. Fiber projections of the putamen also terminate in the pars reticulata of the substantia nigra. Topographical organization of fibers from the putamen to the substantia nigra has not been discerned. Nauta and Mehler (61) confirmed an internal loop of the basal ganglia: putamen-globus pallidus-centromedium 
nucleus-putamen.

4. Efferent Fiber Projections of the Globus Pallidus

Pallidofugal fibers profecting to the midbrain and thalamus represent the major efferent projection from the basal ganglia. These fiber projections are demonstrated in Figure 1B. Efferent fibers from this region compose von Monakow's ansa lenticularis. As described by von Monakow in 1895, the ansa lenticularis is composed of fibers from the lentiform nucleus which perforate the cerebral peduncle and project to the medial region of the thalamus and to the subthalamic nucleus. Three divisions compose the ansa lenticularis: the dorsal division or fasciculus lenticularis, the middle or subthalamic fasciculus and the ventral or ansa lenticularis. The term, ansa lenticularis, tends to be an ambiguous term since it refers collectively to the three divisions of fibers from the globus pallidus as well as the ventral division of the fiber bundle. Von Monakow postulated that the dorsal and middle divisions originated in the putamen and the ventral division originated from the entire lentiform nucleus. Von Bechterew, 1899, proposed that the ansa lenticularis arose from the globus pallidus.

The dorsal division, fasciculus lenticularis, contains fibers from the dorsum of the internal pallidal segment which traverse the internal capsule and contributes fibers to the field $\mathrm{H}_{2}$ of Forel. The middle division or subthalamic fasciculus penetrates the cerebral peduncle as 
part of the "comb system" In a more caudal and ventral

pathway and terminates in the subthalamic nucleus. Nauta and Mehler reconfirmed that this profection which originates in the external pallidal segment (monkey) possibly represents the only source of efferent flber profection from the external segment of the globus pallidus. Efferent fiber profections of the subthalamic nucleus terminate in the internal pallidal segment, thereby forming a loop: external pallidal segment-subthalamic nucleus-internal pallidal segment. Cells In the more ventral portion of the internal pallidal segment contribute fibers to the ventral division, the ansa lenticularis. These thick fibers from the ventral division project dorsally along the medial edge of the internal capsule to field $\mathrm{H}_{2}$ of Forel in the subthalamic region. At the subthalamic level, a division occurs in which the mafority of flbers reascend forming field $\mathrm{H}_{1}$ of Forel (F1gure 1B). This division profects to the ventral aspect of the thalamus and terminates in the centrum medianum, nucleus ventralis anterior and ventralis lateralis of the thalamus. This latterfiber profection to the thalamus is also termed fasciculus thalamicus. Fiber termination of pallidal axons occurs in the pars principalis of the nucleus ventralis anterior which in turn profects to areas 6 and 8 of the cerebral cortex. Thalamo-cortical fiber profections are represented in Figure 1C. The pallidal fiber profection to the nucleus ventralis lateralis terminates in the pars 
oral1s, which in turn projects to area 4 of the cerebral cortex. These thalamic nucles then are related to the motor cortex, thereby forming a cortical-basal ganglia-thalamiccortical loop.

A second efferent fiber profection from the globus pallidus terminates in prerubral areas and the substantia nigra. At the level of the branching of the fasciculus thalamicus from the ansa occurs a fiber profection from the fasciculus lenticularis which terminates in Forel's fleld $H$ in the prerubral area and a few fibers terminate in the pars compacta of the substantia nigra. A direct, but sparse, pallidorubral projection in the cat was postulated In the cat. In Nauta and Mehler's extensive studies, no flber projection from the globus pallidus beyond the mesencephalon was noted.

As is evident from the above discussion, the existence of complex loops provides various pathways for corticalbasal ganglia integration. The centrum medianum, which recelves a fiber projection from the motor cortex and the entire neocortex converge upon the caudate nucleus and putamen. The striatum in turn profects to the globus pallidus. The globus pallidus projects to the subthalamic nuclues, nuclel ventralis lateralis and ventralis anterior of the thalamus. In turn, the subthalamic nucleus projects to the Internal pallidal segment, and nuclel ventralis lateralis and ventralis anterior profect to cortical area 4 
and cortical areas 6 and 8 , respectively. B. Ablation Studies Involving the Basal Ganglia

Lesioning within an area may be regarded as a release phenomenon in which expression of the intact systems occur or lesioning may be regarded as a deficlt in activity due to the termination of influences from the ablated structure. Ablation techniques employed in the investigation of the caudate nucleus or globus pallidus offer little lnformation unless extensive bilateral lesions are produced. Objections to ablation include: (1) the inability to restrict the lesion to the particular designated structure due to the fact that secondary effects such as disruption of vascular supply which could result in necrosis in areas distant to the lesion or such as removal of the cortex in order to approach the caudate nucleus; and (2) difficulty in interpretation when two complex areas such as the cortex and basal ganglia are ablated. Difficulty arises in attributing dysfunction to a particular structure such as the cortex or basal ganglia due to the complex interactions not only between these structures ablated but also between these and other cortical or subcortical regions.

Mettler and Mettler's (57) Investigation of striatal ablation indicated that early detectable signs were not produced with small unflateral striatal lesions; but extensive bllateral lestons produced motor release phenomena characterized by hypertonia and hyperkinesia such as circling. 
From ablation studies they suggested that the striatum had an Inhibitory influence upon the cortex. Therefore, removal of this area resulted in hyperactivity.

Removal of various regions of the basal ganglia and cerebral cortex was employed by Kennard, 1944 (43), In an attempt to relate physlological research with clinical concepts. Deficits in motor activity due to removal of various cortical areas had been previously described. Therefore additional deficits that occurred following combined cortical-basal ganglia lesions could be partially attributed to basal ganglia dysfunction. Removal of cortical area 6 produced spasticity, transient paresis and defictt in grasp reflex, whereas flaccldity was the mafor post-operative characteristic of area 4 removal. Ablation of area 8 in the monkey produced a stooped posture and a flxed gaze which was followed by motor hyperactivity. Unilateral or bilateral removal of the caudate nucleus or putamen produced no evident post-operative symptoms in monkeys or chimpanzee. Removal of the caudate nucleus or putamen in confuncture with area 6 of the cerebral cortex produced spasticity slightly greater than that observed with ablation of cortical area 6 alone. A transient paresis and deficit in grasp reflex attributed to cortical area 6 lesion was present as well as tremor attributed to caudate nucleus dysfunction. Tremor was greatest at the onset of movement and diminished towards termination of movement. The tremor described has been 
termed activity tremor since no tremor occurred during complete rest. Tremor resulting from combined lesions of cortical area 4 and the caudate nucleus was reduced due to paresis attributed to area 4 ablation. Parkinsonian tremor In man has been diminished or abolished by lesioning in area 4 as well as lesioning within the ventralis lateralis and ventralis anterior of the thalamus. The underlying mechanism in the reduction of tremor was attributed to the resulting hemipares1s. The role of background activity for posture and movement was then attributed to the basal gangl1a. Therefore, ablation of this area terminated background activity necessary for voluntary movement and tremor and other locomotor dysfunctions resulted.

Davis, 1958 (10), V11lablanca and Marcus, 1973 (82), and Mettler, 1973 (54), ablated the caudate nucleus to observe total locomotor activity as well as to deduce behavioral Implications. Monkeys developed locomotor hyperactivity. No forced clrcling was observed, but forced pacing in confined quarters was evident. Hyperactivity in cats was identified by a tracking phenomenon in which a moving object was followed visually or by locomotion. A decrease in hyperactivity was evident during sleep. As was evident from the above description discrete lesioning within the basal ganglia did not produce dysfunctions as those observed in the clinic. Massive destruction was needed to produce hypertonia, hyperkinesia and circling which are characteristics of basal ganglia 
lesioning in animals.

C. Electrical Stimulation of the Basal Ganglia

Electrical stimulation of the caudate nucleus has produced a variety of responses including contraversive head turning, c1rcling, contralateral fore $11 \mathrm{mb}$ and hind $11 \mathrm{mb}$ flexion (23), a "melting" away or inhibition of cortically Induced $(55,59)$ or spontaneous movement (25). Electrical stimulation consisted of two types: stimulation within the subcortical area alone, and the conditioning-test technique In which basal ganglia influences upon pre-existing motor activity were observed. Mettler, et a 1. (56), the first to employ the conditioning (caudate nucleus)-test (cortex) technique in the investigation of the basal ganglia, obtalned Inhibition of cortically induced fore limb flexion. This technique provided a fruitful method for the investigation of subcortical modulation of pre-existing motor activity. A second type of conditioning-test technique involved basal ganglia influences upon reflex activity. Both facilitatory and inhlbitory influences from the caudate nucleus and globus pallidus were observed upon reflex-1nduced knee Jerk and cortically induced fore limb flexion. Fac1litation and Inhibition of reflex activity occurred from identical regions within the caudate nucleus. Hodes and Peacock ( 32 , 65) postulated the role of the caudate nucleus as an inhib1tory area which acted in a unilateral manner through the suppressor cortex and acted in a bilateral manner through 
the hypothalamus and medial reticular formation upon the spinal leve1.

Recent investigation of caudate nucleus modulation of cortically induced hind $11 \mathrm{mb}$ flexion conducted by Liles and Davis $(50,51)$ demonstrated the rostral portion of the caudate nucleus inhibited cortically induced flexion activity, whereas the caudal portion of the caudate nucleus facilitated a cortically induced flexion response (measured indirectly by myogram tension). An increase in stimulation intensity within the rostral area enhanced the cortically induced locomotor activity. This enhancement was attributed to current spread to facilitatory regions of the caudate nucleus.

Responses evoked from the caudate nucleus are not only related to the area stimulated but also to the frequency of stimulation. Responses elicited by the caudate nucleus resulting from various frequencles of stimulation are categorized into three groups: (1) low frequency range, one cycle per five seconds to ten cycles per second during which inhibition occurred; (2) middle frequency range, twenty to thirty cycles per second during which an arrest reaction occurred; and (3) high frequency range, frequency greater than thirty per second to greater than three hundred per second during which desynchronization of cortical activity occurred. 
A single shock, up to ninety volts, delivered to the head of the caudate nucleus produced in the precruciate region of the cortex a short latency evoked potential followed by a series of high voltage oscillations termed "caudatespindles" (29). These spindles having a latency of 200 to $245 \mathrm{msec}$ when recorded in the 1psilateral precruciate cortex may last three seconds. In unanesthetized preparations these spindles occurred at a frequency of ten to twelve cycles per second. The 1psilateral precruciate region was the predominant region for recording "spindles", although "caudate-spindles" were recorded in other cortical sites as well as the thalamus, globus pallidus and contralateral caudate nucleus. Although "caudate-spindles" were independent of background cortical activity, a lower threshold voltage was necessary to elicit "spindles" In an animal which exhibited a synchronyous EEG. Lesloning the ventralis anterfor nucleus of the thalamus discupted spindle production while the evoked potential remalned intact, thus demonstrating that the integrity of the thalamus was necessary for spindle production. The subcortical area that elicited the evoked potential and "caudate-spindle" was disputed among researchers. Due to the approximation of the internal capsule and caudate nucleus, Goldring (25) presented evidence that stimulation of the caudate nucleus resulted in spread of current to the Internal capsule. Therefore, activation of caudatecortical projections within the internal capsule occurred. 
On the other hand, Horvath and co-workers (33) demonstrated that threshold values of electrical stimulation for eliciting "caudate-spindles" In the cortex were significantly lower in the caudate nucleus and caudate nucleus-internal capsule border, than in the internal capsule.

Buchwald, and co-workers $(2,7,8,30)$ proposed a "caudate loop", and "Inhibitory" loop based upon data obtained from low frequency caudate nucleus stimulation and "caudate-spindle" production. They also attempted to relate the caudate loop to behavioral observations resulting from caudate nucleus stimulation. Low frequency stimulation of one shock per five seconds produced slow wave EEG activity. The cat passed from an alert state into a state of drowsiness or resting which was referred to as an inhibitory state. The proposed "Inhibitory" loop from the caudate nucleus to the VA-VL of the thalamus and to the cortex has been postulated to antagonfze the arousal system of the reticular formation. Stimulation within the caudate nucleus at a frequency of twenty to thirty cycles per second produced an arrest reaction as evident by cessation of a task. A slow turning of the neck and trunk to the side as though the animal was looking caudalward could result and prolonged stimulation could maintain this position ( 30$)$.

High frequency stimulation within the caudate nucleus produced desynchronization of the EEG related to behavioral responses representing alerting or arousal ( 30 ). As in the 
case of the inhibitory response evoked by caudate nucleus stimulation, the facilitatory responses were also dependent upon the integrity of the ventralis anterior of the thalamus. Therefore, both facilitatory and inhibitory modulation of cortical activity by the caudate nucleus are mediated at least in part via the nucleus ventralis anterior. Chronic preparations, then, provide a technique for the analysis of the basal ganglia in intact, unanesthetized and unrestrained animals.

These behavioral results have also been related to intracellular and unitary cortical responses. A single shock to the caudate nucleus evoked a short depolarizing response followed by a long hyperpolarizing response in cortical cells. The characteristic long hyperpolarizing phase has been Interpreted by Hull (36) as a mechanism for the reduction of synaptic nolse and enhancement of excitatory inputs. A slow postive DC shift accompanied the long, hyperpolarizing phase which lasted 100 to $200 \mathrm{msec}$. If the caudate nucleus shock was palred with a shock from an afferent source (visceral or somatic) within a critical time interval, the prolonged inhibitory response (IPSP) observed in the cortical neuron was shortened. A 70 msec time interval was the critical time value during which the shortened IPSP occurred (37). "Disinhibition" was the term describing the decrease in the inhibitory period. Disinhibition was dependent not only upon the time interval between the caudate nucleus 
shock and afferent shock, but also upon the number of pair1ngs. Repeated palrings of shocks decreased the disinhibition phenomenon. Pairing two caudate nucleus shocks within a 70 msec interval reset the inhibitory period in which an EPSP and some instances cell firing occurred in response to the second shock delivered to the caudate nucleus, but an Increase in the overall inhibitory duration followed. As is evident, repetitive stimulation to the caudate nucleus produces complex facilitatory and inhibitory responses at the cortical level which are consistent with the complex behavioral responses also produced by caudate nucleus stimulation.

D. Intracellular and Unit Activity of the Caudate Nucleus and Lentiform Nucleus.

Recording activity within the caudate nucleus has not only alded in the analysis of temporal and spatial interrelations of various structures upon the basal ganglia, but has provided physiological confirmation of striopedal pathways. Kemp and Powe $11(40,41)$ have Investigated synaptic terminations of striopedal axons. Although distribution of extrinsic axons was throughout the caudate nucleus, axon terminals of both the cortical and intralaminar nuclei profections form clusters or groups within the caudate nucleus. Lesioning studies involving the lateral and medial surfaces of the cerebral cortex demonstrated degeneration of 0.6 to $2.0 \mu m$ diameter, finely myelinated axons which form 
synapses with asymmetrical membrane thickenings on dendritic spines. Some extrinsic fibers form en passant connections. Since these thin axons were not detected in Wilson's histological preparations, he postulated that the basal ganglia were independent of the cerebral cortex. Simflarly, lesioning within the intralaminar nuclei resulted in degeneration of 0.5 to $2.5 \mu \mathrm{m}$ diameter, thinly myelinated axons which form synaptic connections with asymmetrical membrane thickenings predominately upon dendritic spines. From the above described lesioning studies and flber connections, Kemp and Powell postulated that all profections to the caudate nucleus that form synapses with asymmetrical membrane thickenings represented extrinsic axons and therefore the axonal connections with symmetrical membrane thickenings represented intrinsic fibers. The mafority of the intrinsic axons terminate on dendritic shafts or upon non-spiny regions of the intracaudate neuron. Furthermore, Kemp and Powell (39) proposed that round vesicles located in boutons with asymmetrical membrane thickenings were assoclated with excitation or EPSP (exc1tatory postsynaptic potential) activity, whereas those boutons with flat vesicles and symmetrical membranes were associated with IPSP (Inhibitory postsynaptic potential) activity. Their contention was strongly supported by data demonstrating that Intracellular responses of the caudate neuron to extrinsic, cortical or thalamic stimulation was an initial EPSP followed 
by a long IPSP. This EPSP-IPSP sequence was paralleled by findings that the EPSP would result from direct synaptic connections from extrinsic profections and the IPSP response would result from neighboring intracaudate synaptic effects. A characteristically low spontaneous activity in the caudate nucleus has been reported by Buchwald, et al. (4), Rocha-Miranda (68), Purpura (67), and Sedgwick and Williams (71), although the latter authors described a regular burst pattern of some units with a 100 to 120 msec burst interval. Intracellular recordings by Hull, et al. (34) also described a low frequency of firing or silent periods of caudate neurons. A comparison of caudate neuronal activity in the unanesthetized versus anesthetized preparations demonstrated that low spontaneous discharge was not a result of anesthesia. Spontaneous activity was similar in both chloralose and nembutal preparations although Segwick and Williams reported more active units with chlorasose anesthesia. In deep chloralose anesthesia spontaneous activity was absent, whereas in $11 \mathrm{ght}$ chloralose $(60-80 \mathrm{mg} / \mathrm{kg})$ or nembutal (35 $\mathrm{mg} / \mathrm{kg})$ anesthesia, spontaneous activity was considerably less than in the unanesthetized preparation (1). Terminology characterizing 1 ight anesthesia varied among researchers and therefore tended to be ambiguous.

Fluctuations in the resting membrane polarization level have been noted in which depolarizing or hyperpolarizing membrane shifts up to 5 mv occurred and were maintained for 
several seconds to several minutes. The length of time the cell was impaled did not correlate with the length of the polarizing membrane shifts. Responses to stimulation also varied during the membrane potential shifts. During a positive depolarizing membrane potential shift, the cell would spontaneously fire, whereas during a negative membrane potential shift electrical stimulation of the cell would not necessarily elicit an action potential.

Three postsynpatic responses characterize caudate neuronal responses to various stimulation sites (6). These responses Include: (1) a relatively "pure" EPSP, a response elicited in thirty to forty per cent of the caudate cells In response to centromedial-parafascicularis stimulation; (2) EPSP-IPSP sequence, the most predominant response of caudate cells, and (3) a "pure" IPSP, a relatively rare occurrance. The duration of the EPSP ranges from 5 to 50 msec whereas the IPSP was considerably longer in duration, ranging to 200 to $300 \mathrm{msec}(6)$. One spike was the characteristic response to a single shock rather than a burst of spikes, but more frequently, large amplitude EPSP's without a spike occurred. These responses elicited in the caudate nucleus resulted from stimulation of the three input areas, the cortex, Intralaminar nuclei and the substantia nigra. Extracellular responses of caudate units to peripheral stimulation demonstrated that units respond to stimulation 
of the four limbs. No units responded to stimulation of the nerve to the hamstrings, which would indicate no proprioceptive input from the perlphery. Generally, cortically induced IPSP's were longer in duration than those elicited by the rostral thalamus. The duration of the sequence was longer for cortical stimulation than thalamic stimulation, and response duration to nigral stimulation was the shortest in duration. An increase in stimulus intensity elicited an increase in amplitude of response rather than in duration to the various stimulus sites could not be attributed to stimulus intensity.

Caudate neuronal responses also varied with increasing frequency of stimulation. Caudate cells responded with rhythmic membrane responses when various areas were stimulated at a frequency of one cycle per second to ten cycles per second. At frequencles greater than ten cycles per second long duration hyperpolarizations were evident during the period of stimulation. This response occurred with stimulation to thalamic, cortical and brain stem areas.

Frequencles greater than 100 cycles per second delivered to various areas produced a marked depolarization in which an increase in cell firing was evident. One to two seconds following termination of the stimulus train, a decomposition of spikes occurred with a further depolarization. Thus increasing frequency of electrical stimulation produced more complex membrane potential changes (34) than those observed 
with low frequency stimulation.

Palring of afferent stimuli to the caudate nucleus also produced a variety of responses dependent upon the site of stimulation as well as the time interval of the pairings. Hull, et al. (35) Investigated interactions of various stimulation sites, le, cortex, substantia nigra and thalamus. As stated previously the most common response recorded in the caudate nucleus neurons was an EPSP-IPSP sequence. When the two stimuli were presented simultaneously to a stimulus s1te, an increase in amplitude of both the EPSP and IPSP with no variation in duration occurred. When the test EPSP colncided with the conditioning EPSP, a decrease in the amplitude of the test EPSP was noted. If the test EPSP colncided with the conditioning IPSP, then an increase in the amplitude of the test EPSP occurred.

Conditioning and test stimuli delivered to different anatomical locations produced similar responses in caudate cells as described above, although cortical stimulation tended to be the predominant influencing factor. If a cortical and subcortical stimulus colncided, the resultant EPSP activity of the caudate nucleus neuron would summate. On the other hand, if a subcortical stimulus was temporally placed so that the EPSP colncided with the cortical IPSP, then the EPSP would be diminished or not evoked. This result indicates a prepotent cortical modulation of subcortical input to neurons of the caudate nucleus. 
From the above information a model was formulated whereby integration within the caudate nucleus was based upon organization of the synaptic terminals of extrinsic fibers and the intracaudate neuron (39). Assumptions from Hull, et al. and Kemp and Powell Include that: (1) all extrinsic axons are excitatory and terminate mainly upon dendritic spines; (2) cortical and thalamic inputs tend to coverge upon common cells; (3) the intracaudate neurons are of an Inhibitory nature; and (4) the efferent caudate nucleus profection is mainly inhibitory upon the globus pallidus although some excitatory output to the pallidum is also evident. Information then from the cortex, thalamus, and substantia nigra is exc1tatory. This input evokes EPSPIPSP sequences in caudate neurons. The IPSP activity is a result of stimulation of nelghboring inhibitory intracaudate neurons. The intracaudate neuron represents ninety-six per cent of the caudate cells and therefore partly accounts for the low spontaneous firing rate of caudate neurons (36). Outflow from the caudate nucleus both excltes and inhibits the globus pallidus; the functional consequences of this modulation w111 be discussed later.

A characteristic difference within the basal ganglia is a high rate of spontaneous activity in the lenticular nucleus cells as compared to low spontaneous activity of caudate nucleus cells. Spontaneous unit discharge varied within the lenticular nucleus and in some instances is 
greater than forty pulses per second in the putamen (72). Noda, et al. (63) categorized spontaneous cell firing into high discharge rate, low discharge rate and repetitive bursting. Those units which exhiblted a high discharge rate generally demonstrated convergence of afferent input, responding to sensorimotor cortex, midbrain reticular formation and nucleus centrum medianum stimulation. Units which exhibited a low discharge rate generally exhibited a response to only one stimulus site.

Most lenticular neurons respond to both medial thalamic and caudate nucleus stimulation by exhibiting an EPSP-IPSP sequence to repetitive caudate nucleus stimulation (52). A short and often Interrupted EPSP usually preceedes the 50 to 100 msec duration IPSP which exhibits a latency of 10 to 20 msec. High frequency stimulation delivered to the caudate nucleus produces IPSP summation and therefore sustained membrane polarization in the ventral regions. These cells generally exhibit IPSP responses to medial thalamic stimulation.

In summary, the basal ganglia are involved in a complex circuit in which information from the cortex, thalamus, and substantia nigra are modulated by temporal and spatial interactions within the caudate nucleus. This modulated Information Impinges upon the globus pallidus mainly evoking IPSP activity within this subcortical structure although some excitation results. The globus pallidus in turn profects 
to the thalamus and prerubral areas which influence cortical and spinal level, respectively.

1. Activity of Lenticular Neurons during Movement

The basal gangl 1a were assumed to be involved in background activity for movement. Mettler, et al. (47), established the first technique for the examination of basal ganglia activity upon cortically induced movement. Evarts, (19) devised a technique to record unit activity in subcortical structures during a movement. This technique provided a method for recording unit activity prior to the onset of movement to the termination of a task related movement. Therefore, the temporal sequences of units in various structures could be analyzed in a chronic preparation during a movement. Delong examined the activity of lenticular units in monkeys during a push-pull task $(11,12,13)$. During rest, the putamen exhibited a lower level of spontaneous firing than pallidal neurons which exhiblted a high discharge rate. Neurons of the internal pallidal segment were distinguishable from those of the external pallidal segment. The mafority of units recorded in the external pallidal segment exhibited two types of activity. Some units exhibited periods of high frequency discharge separated by silence, whereas other units exhibited a low discharge level with a burst pattern. These types of activity were observed by Noda (63) in the anesthetized, but 1 mmobilized cat. 
One group of monkeys were trained to perform a rapid alternating limb movement, a push-pull task or a side to side movement. Unit activity in both segments of the globus pallidus was recorded. In most units an increase in discharge frequency above the resting discharge rate occurred. Although units responded to both types of movement, they preferentially responded to only one type of movement. No consistent correlation between an increase in cell firing and type of movement was evident during ipsilateral movements. The mafority of movement related units were located in both segments of the contralateral globus pallidus. More specifically, the units related to arm or leg movements were located in the lateral portion of both pallidal segments. Only rarely would a unit respond to both arm and leg related movements. This organization of units in the lateral portion of the globus pallidus appeared related to the anatomical organization demonstrated by Kemp and Powell in the monkey. The lateral portion of the caudate nucleus and putamen receive profections from the sensorimotor cortex. These striatal areas profect in an essentially topographical manner to both segments of the globus pallidus.

The most distinguishing feature was the temporal relation between the task related movements and unit discharge. Numerous units increased discharge rate prior to movement. During movements, many pallidal neurons responded consistently 
throughout movement. Some units discharged predominately during the flexion phase of movement, whereas others discharged predominately during the extension phase of the movement. Change in unit activity was correlated to movement rather than the signal presentation for the initiation of movement. Delong was not able to demonstrate that the increase in pallidal activity occurred prior to activity in the cerebellum or cerebral cortex. The evidence presented for unit activity prior to the onset of movement could possibly Indicate pallidum particlpation in "voluntary movements".

Putamenal units responded preferentially to slow rather than rapid movements. As in the case of pallidal units, the units in the putamen consistently changed discharge rates in relation to the movements (11). Many of these units responded to slow movements in both directions, but did not respond to rapid movements. This observation can be related to Involuntary movements such as chorea, and athetos is (44). Parkinsonian patients have difficulty in the inftiation of movement, whereas rapld movements are less 1mpaired (44).

In this survey, the conceptual development of the basal ganglia from participation in background motor activity to participation in the inftiation of voluntary movement has been considered. As previously described, the basal ganglia form a complex circult modulating both cortical and subcortical motor activity. The present experiments were designed to further assess the functional roles of these two 
modulating circults. 
METHODS

Fifty cats ranging in weight from 2.7 kilograms to 4.2 kilograms were used in the study. Two basic types of experimental preparations were employed. (1) The animal was maintained under $11 \mathrm{ght}$ anesthesia (sodium pentobarbital). Modulation of cortical induced and pyramidal tract induced hind limb flexor responses by electrical stimulation of the basal ganglia was investigated. In this preparation the measured parameters were Ia afferent dorsal root activity, myogram and EMG activity of the anterior tibialis muscle. (2) The unanesthetized preparation, ether was administered during the surgical procedure. Following surgery, ether was discontinued, a local anesthetic was applied to wound edges and pressure points. The animal was immobilized with gallamine triethiodide (Flaxedil) and maintained by artifical respiration. Modulation of direct and indirect pyramidal tract responses elicited by a conditioning (caudate nucleus)test (cortex) technique was recorded in this preparation. A. Anethetized Preparation

An intraperitoneal infection of sodium pentobarbital (Nembutal), $30 \mathrm{mg} / \mathrm{kg}$, was used to anesthetize the cat for the duration of the surgical procedure. A cat was considered sufficiently anesthetized when a withdrawal response from a nociceptive stimulus, pinching between the toes, was not evoked. A T-shaped plastic tracheal cannula was inserted 
Into the trachea and P.E. 190 polyethylene tubing was inserted into the right femoral vein. Cannulation of the vein served as an entry for the administration of sodium thiamylal (Surital) and 5\% dextrose in water solution. Periodic infections of dextrose were administered throughout the experiment. EKG and temperature were continuously monitored. Rectal temperature was maintained within a range of $35.5^{\circ} \mathrm{C}$ to $38^{\circ} \mathrm{C}$ by a hot water heating system in contact with the ventral surface of the animal. During the course of the experiment the cat was maintained under light anesthesia as evident by a withdrawal response to a nociceptive stimulus. If spontaneous movement occurred, a supplemental dose of 0.4 cc of $2.5 \%$ sodfum thlamylal was administered intraveneously.

1. Surgical Procedures

\section{a. Exposure of the Bulbar Pyramids}

The ventral aspect of the cranium was attained by placing the cat in a supine position and ligating and reflecting the sternomastoldeus and the sternohyoldeus muscles, trachea and esophagus. Rongeurs were used to remove the basocclpital bone, thereby exposing the pyramidal tract rostral to the decussation of these fiber tracts. Frequently, bleeding was encountered from an epidural membrane overlying the basoccipital bone and altas. Packing this area with gelfoam prevented oozing of blood into the surgical field. 
b. Denervation of the Hind Limb and Dissection of the Anterior Tiblalis Muscle

The left hind $11 \mathrm{mb}$ was partially denervated by dissecting the nerves from surrounding tissue, identifying, and cutting each nerve. These included nerves to the hamstring muscles, the tiblal nerve, the surals, the superficlal peroneal nerve, the obturator nerve and the femoral nerve. The common peroneal nerve was traced by following its course on the lateral aspect of the hind $11 \mathrm{mb}$ to the peroneus longus muscle in order to expose the nerve to the anterior tiblalis muscle. At this point, the superficlal peroneal nerve was located and cut. Other branches of the common peroneal nerve including the nerve to the anterior tiblalis muscle were 1 dentified and remained intact, thereby eliminating excessive manipulation of the nerve to the anterior tibialis muscle.

The anterior tiblalis muscle was then dissected free from surrounding tissue. Skin overlying the ankle folnt and anterior tiblalis muscle was reflected. Blunt dissection was employed to free the tendon of the muscle and the transverse crural ligament overlying the tendon was cut. A pouch was made by suturing skin over the anterior tiblalis muscle. During the experiment the pouch was filled with mineral o 1 at a temperature of $37^{\circ} \mathrm{C}$ in order to keep the muscle warm and prevent drying. 


\section{c. Framing the Cat}

Upon completion of surgery, the cat was removed from the surgical table and placed in a Kopf stereotaxic and spinal apparatus. Ear bars were inserted bilaterally into the external auditory meatus. Clamps were placed on each Infra-orbital ridge and upper palate to assure firm head position. A vertebral clamp was attached to a thoracic supraspinous process and $s 1 x$ steel pins were placed bilaterally into lumbar vertebrae bodies and then attached to the spinal frame, thereby securing the thoraco-lumbar area. In order to maintain the hind quarters and proximal portion of the left hind $11 \mathrm{mb}$ in a fixed position during the experiment, pins were screwed into the greater trochanter of each femur and a pin was placed in the shaft at its distal end of the left femur. These pins were then attached to the spinal frame.

\section{d. Laminectomy and Preparation of the Dorsal Root}

A midsaggital incision through skin, superficial and deep lumbodorsal fascla was made from $L_{3}$ to $S_{1}$. Blunt dissection was used to remove the lumbar multifidus, lumbar interspinales, longissimus dorsi and intertransversaril dorsalis muscles overlying the vertebral column from $\mathrm{L}_{3}$ to $\mathrm{S}_{1}$. The dissected muscle was tied and secured to the spinal frame in order to expose the vertebral column and to form a trough for warm mineral o1l. Vertebrae overlying 
spinal segments $\mathrm{L}_{3}$ to $\mathrm{S}_{1}$ were removed. A midsaggital incisIon was made in the dura mater and the dura mater was then sutured to the muscle. Warm mineral o $11\left(37^{\circ} \mathrm{C}\right)$ covered the spinal cord to prevent drying. The pla mater was excised and the sixth lumbar dorsal root identified. A very small fllament of this dorsal root was cut centrally and placed over a bipolar, silver recording electrode.

\section{e. Exposure of the Cortex}

Skin overlying the cranium was reflected. A hole, drilled in the right side of the dorsal aspect of the cranium, was enlarged with rongeurs to expose the orbltal, sigmold, marginal and suprasylvian gyri. The dura mater was reflected and an agar barrier surrounded the surglcal opening in order to contaln a mineral ofl pool overlying the exposed cortical surface. The warm mineral ofl was changed periodically in each pool throughout the experimental day to maintain a temperature of $37^{\circ} \mathrm{C}$.

\section{Recording Procedure}

As previously described, a thin filament of the sixth lumbar dorsal root was placed over a blpolar, silver recording electrode. Action potentials of the fllament were amplified with a Tektronix 122 low-level preamplifier and monitored on a Tektronix 502 dual-beam oscilloscope. The signal was further amplified with a Grass P5 preamplifier and stored on magnetic tape on one channel of a four channel Ampex tape recorder. In addition to visual monitoring, an audio system 
was employed to hear the frequency of firing of the action potentials recorded from the dorsal root fllament. The fllament was continually divided with the ald of audio and visual monitoring of the rootlet until a single filament remained containing a Ia afferent fiber from a muscle spindle located in the anterior tibialis muscle. Ia and Ib fibers are difficult to differentiate on the basis of passive stretch and conduction velocity. Therefore, this differentiation was made by electrical stimulation at a frequency of one pulse every two seconds, with a pulse duration of $1.0 \mathrm{msec}$ and a stimulus intensity of sufficient voltage to produce a twitch contraction. Since the Golgl tendon organ lies in series with extrafusal muscle fibers, the Ib afferent fiber from this organ conducts action potentials during the rising phase of the twitch contraction. On the other hand, the muscle spindle, lying in parallel with extrafusal muscle fibers does not elicit action potentials during the rising phase of a twitch contraction. This period during which no action potentials are recorded from a Ia afferent fiber of a muscle spindle is termed the silent period $(27,53)$. An afferent fiber of a muscle spindle was also differentiated from an afferent fiber of a Golgl tendon organ on the basis of response to electrical stimulation of the sensorimotor cortex and pyramidal tract. The gamma motoneuronal system, the motor Innervation of the muscle spindle, may be activated by cortical stimulation at stimulus intensities sufficient to 
enhance gamma discharge and thus Ia afferent discharge, but not sufficlent to activate the alpha motoneuronal system as evident by no change in myogram tension or EMG activity (26). Therefore, those afferent fibers exhibiting a silent period during a twitch contraction and also responding to cortical stimulation were considered Ia afferent fibers from the muscle spindle. Those afferent fibers which did not exhibit both characteristics, le, silent period during twitch contraction and enhancement of firing in response to cortical stimulation, were not used in the experiment.

Figure 2 demonstrates the location of stimulating and recording electrodes. A bipolar, ball-tipped, stainless steel stimulating electrode was placed on the surface of the contralateral sensorimotor cortex. Location of the hind $11 \mathrm{mb}$ area was obtalned by delivering constant current pulses of $1.0 \mathrm{msec}$ pulse duration at a frequency of 60 cycles per second and a current intensity of $0.8 \mathrm{~mA}$ to the cortex. The sensorimotor cortex was stimulated at various points until an increase in the rate of the anterior tibialis Ia afferent dorsal root discharge occurred. A stainless steel, bipolar, bal1-t1pped electrode was placed, under visual control (with a mirror), on the ventral surface of the contralateral pyramidal tract. Location of the electrode was confirmed by observing an Increase in dorsal root discharge upon a volley of electrical shocks delivered to this area 
Figure 2 Diagram of the Experimental Arrangement of Stimulating and Recording Electrodes in the Anesthetized Preparation (explanation in text)

Abbreviations are as follows:

S: BG - caudate nucleus or globus pallidus stimulating electrode

S: Cx - cortical stimulating electrode

S: Pt - pyramidal tract stimulating electrode 


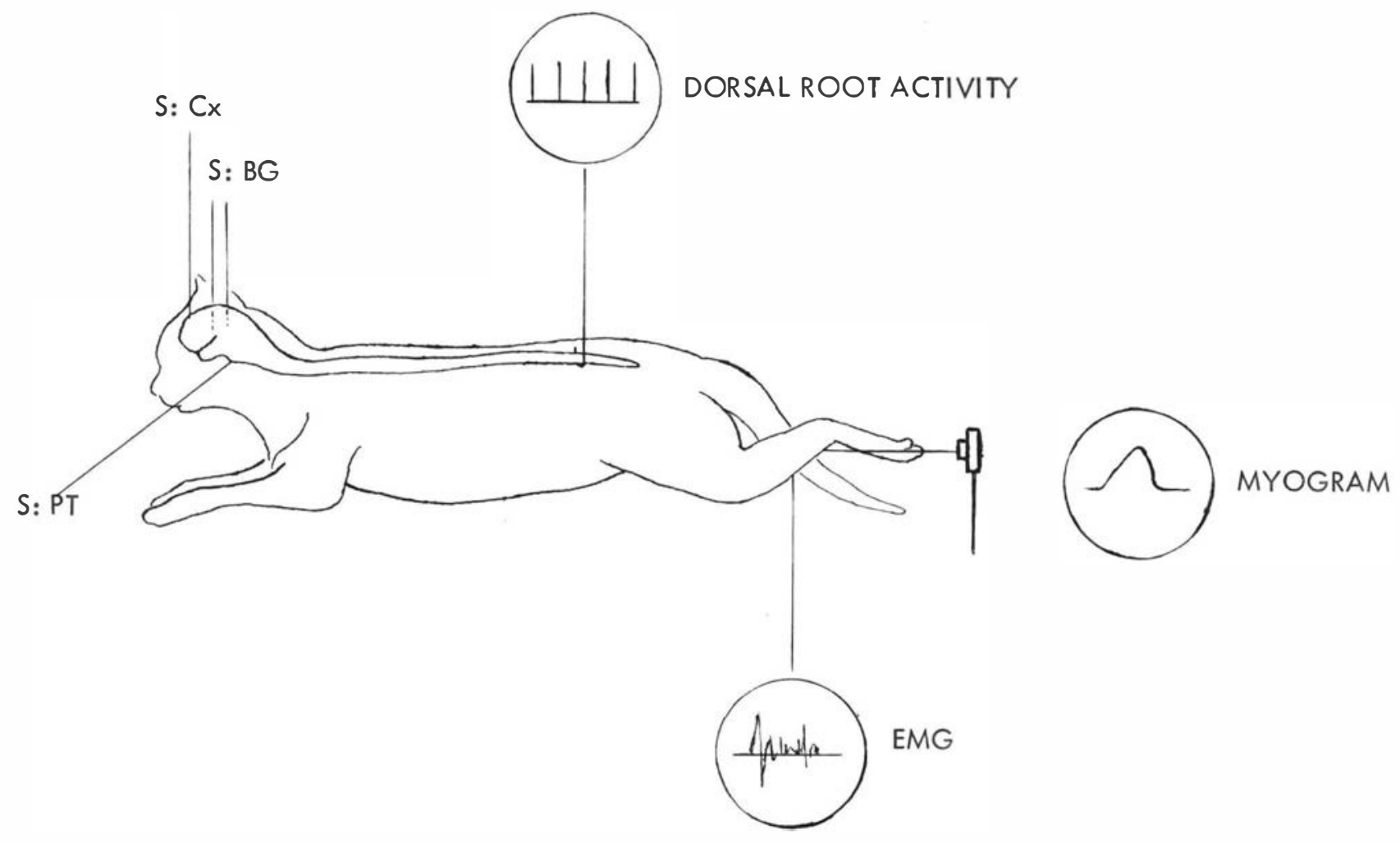


at a frequency of 60 cycles per second, a pulse duration of $1.0 \mathrm{msec}$ and a current intensity of $0.8 \mathrm{~mA}$. Five type 00 stainless steel insect pins were insulated with Insl-X to within 0.5 millimeters from the t1p and were separated at one millimeter intervals into an array or "comb" of electrodes. With the ald of a stereotaxic atlas (Snider and Nieman, 75) this "comb" was stereotaxically placed within either the caudate nucleus or globus pallidus.

The distal end of the tendon of the anterior tiblalis muscle was sectioned and tied by means of a thread to a Grass FT 03 force-displacement transducer. A ten gram tension was maintained on the muscle to prevent slack in the system. An EMG needle elctrode was placed in the belly of the anterior tibialis muscle. Signals of both the myogram and EMG were amplified, monttored on a Tektronix 502 oscilloscope and stored on magnetic tape.

\section{Experimental Format}

Flexor responses to shock trains delivered to the precruclate cortex were recorded. A constant current pulse train with a pulse duration of $1.0 \mathrm{msec}$, a frequency of 60 cycles per second and a train duration of 500 or 1000 msec was delivered to the cortex. The intensity of the stimulus was adfusted until a minfmal increase in dorsal root discharge was detected, a response which indicated that only the gamma system was activated. Intensities required to elicit this response ranged from $0.5 \mathrm{~mA}$ to $2.0 \mathrm{~mA}$. All 
stimulations were made at two minute intervals since $1 t$ was found that repetitive stimulation of the cortex elicited long term facilitatory effects upon Ia afferent dorsal root discharge. If the cortical responses demonstrated falrly consistent increases in Ia afferent dorsal root discharge, then appropriate tests using trains of shocks delivered simultaneously to the cortex and one locus within either the caudate nucleus or globus pallidus were employed. The train of pulses to the subcortical structures consisted of square wave pulses, a pulse duration of $0.5 \mathrm{msec}$, a frequency of 100 cycles per second and a duration of 500 or $1000 \mathrm{msec}$, delivered by a Grass $8 \mathrm{~S}$ stimulator through a stimulus isolation unit and a constant current unit. Stimulus intensities to the caudate nucleus and globus pallidus were well below that wh 1 ch would by themselves modify Ia afferent discharge. Intensities delivered to these subcortical structures ranged from $20 \mathrm{~V}$ to $25 \mathrm{~V}$ or $2.0 \mathrm{~mA}$ to $2.5 \mathrm{~mA}$.

Flexor responses to cortical stimulation alone and to stimulation of the cortex and one locus in the caudate nucleus were compared. For each electrode pair in the "comb" a minfimum of one cortical stimulation and five cortex-caudate nucleus stimulations were performed at regular intervals. Having palred cortical stimulation with each pair of electrodes within the "comb", the experimental format was repeated with palred electrical trains of shocks delivered to the pyramidal 
tract and each pair of electrodes within the "comb". Stimulation to the pyramidal tract consisted of a constant current pulse train with a pulse duration of $1.0 \mathrm{msec}$, a frequency of 60 cycles per second and a duration of 500 or $1000 \mathrm{msec}$. The Intensity of the stimulus required to elicit a minimal increase in dorsal root discharge ranged from $0.5 \mathrm{~mA}$ to $1.5 \mathrm{~mA}$. This series of recordings were followed by trains of electrical shocks delivered to each palr of electrodes within the "comb". Upon completion of stimulation through each electrode palr within a horizontal plane, electrolytic lesions were produced by a DC current of $0.05 \mathrm{~mA}$ for a ten to fifteen second duration delivered by a Nuclear Chicago constant current stimulator to each electrode within the "comb". The electrode was lowered one millimeter and the experimental format repeated. Mapping of the caudate nucleus and globus pallidus was accomplished in this manner.

A series of experiments employing the recording format described above was used in a decorticate preparation. Recording data previous to and following decortication was not feasible due to a high mortality rate. Cats were unable to survive the trauma of decortication after a ten hour surglcal-recording perlod. Therefore, bilateral surglcal ablation of three to four millimeters deep of the entire cortex was completed, and two hours elapsed before the recording began. 


\section{Data Analysis}

The recorded data were filmed on moving Kodak Linagraph paper by a Grass Kymograph camera at a speed of 25 m1111meters per second. Latencies from the onset of stimulation to onset of myogram tension and to the onset of EMG activity as well as changes in the Ia afferent activity were measured. Ia afferent activity was analyzed during one second prestimulus, stimulus, and post-stimulus periods. Changes in afferent activity attributed to paired stimulation of the cortex and caudate nucleus were compared to the Ia afferent activity elicited by cortical stimulation alone. If a forty percent or more increase in Ia afferent activity due to palred cortical-caudate nucleus stimulation above the control cortical response occurred in a minimum of four of the five test (cortical-caudate nucleus) responses, then a "+" was recorded on the appropriate midsaggital map of the caudate nucleus at the location of the electrode tips. Similarly, If a forty per cent or more decrease in Ia afferent dorsal root activity below the control response was recorded in a minimum of four of the five cortical-caudate nucleus test responses, then a "-" was recorded. These criterla were sufficient to conclude that responses at each "+" and "-" locus were significantly different from control responses $(p<0.01, c h 1$ square). If changes in Ia afferent activity were less than forty per cent of the cortical-caudate nucleus test responses, then a " 0 " was placed on the 
appropriate caudate nucleus map at the location of the electrode tips to designate the locus as inactive. The term Inactive refers to the fact that at the stimulus intensities (20-25 volts, $2.0-2.5 \mathrm{~mA})$ employed only slight changes or no changes upon cortically induced activity were observed. Maps of the caudate nucleus were reproduced from midsaggital histological sections of the brain and represented sections located at $2.5 \mathrm{~mm}, 3.5 \mathrm{~mm}, 5.0 \mathrm{~mm}$, and $6.0 \mathrm{~mm} 1$ ateral from the midline.

Similar criteria for assigning "+", "-", and "0" were ut 11 ized for the pyramidal tract-caudate nucleus interactions. Palring of globus pallidus loci with cortical and pyramidal tract stimulation were analyzed and represented in a simflar manner on maps reproduced from idsaggital histological sections located $6.0 \mathrm{~mm}$ and $8.0 \mathrm{~mm}$ from the midilne. B. Unanesthetized Preparation

The animal was placed in a closed box and an ether bottle was introduced in a hole located on the side of the box. When sultably anesthetized, as indicated by the level of ether anesthesia, the animal was placed on a surgical table and a tracheotomy was performed. Throughout the surgical procedure, the cat was maintained by artificial respiration. An ether Jar was connected in parallel with the input from the respirator so that the cat was respired with an ether-air mixture. The amount of ether administered was controlled by adfustment of a screw clamp located between the ether $\mathrm{far}$ and input tube 
from the respirator. A polyethylene cannula was placed in the right femoral vein. All surgical wounds were infiltrated with $5 \%$ lidocaine (xylocaine) ointment. 1. Surgical Procedure

After exposure of the bulbar pyramids, pins were placed bilaterally in each mastoid process, a part of the mastoid portion of the temporal bone. The lamboidal ridge was palpated and followed in a rostro-ventral course to the mastoid process which is in continuation with the outer aspect of the lamboidal ridge. A hole was drilled in each mastoid process, through the outer wall of the tympanic bulla, and a pin screwed into each hole.

The cat was placed in a Kopf sterotaxic and spinal apparatus. Far bars were inserted bilaterally and the head secured as previously described. Xylocaine infiltrated all wounds and pressure points. The A-P stereotaxic zero was notched in the cranium. As previously described, the cortex was exposed and covered with warm mineral oil. Ear bars were then removed and the head supported by the pins that were placed in each mastoid process, thereby removing pressure on points exerted by ear bars. Ether was discontinued, gallamine triethiodide was administered to immobilize the cat, and the cat was artifically respired for the remainder of the experiment. Throughout the experiment FKG and body temperature were monitored. Whenever possible the per cent $\mathrm{CO}_{2}$ of the preparation was monitored and 
maintained at 5.2 per cent by proper adfustment of the respirator. Constriction of the pupils and a synchronyous EEG served as criteria to demonstrate lack of stress in this preparation (1). Reapplication of Xylocalne ofntment to all pressure points and wound edges was made at regular intervals throughout the experiment.

\section{Recording Procedure}

The experimental arrangement of electrode placement is demonstrated in Figure 3. A bipolar, ball-tipped, stainless steel stimulating electrode was placed on the surface of the left precruciate gyrus. A recording electrode, similar to the cortical stimulating electrode, was placed on the ventral surface of the 1psilateral pyramidal tract to monitor the direct and indirect (D-I) responses elicited from a single shock delivered to the cortex. An array of "comb" electrodes simflar to that used in the anesthetized preparation was stereotaxically placed within the caudate nucleus or globus pa111dus.

A single pulse with a 0.1 msec duration was delivered to the sensorimotor cortex and the intensity was adfusted until current levels sifficient to elicit minimal and maximal D-I responses were determined. For the duration of the experiment, a current intensity midway between these two values was employed, so that a change, elther an increase or decrease in response, could be detected. Stimulus intensities ranged from $0.5 \mathrm{~mA}$ to $2.0 \mathrm{~mA}$. This stimulus was 


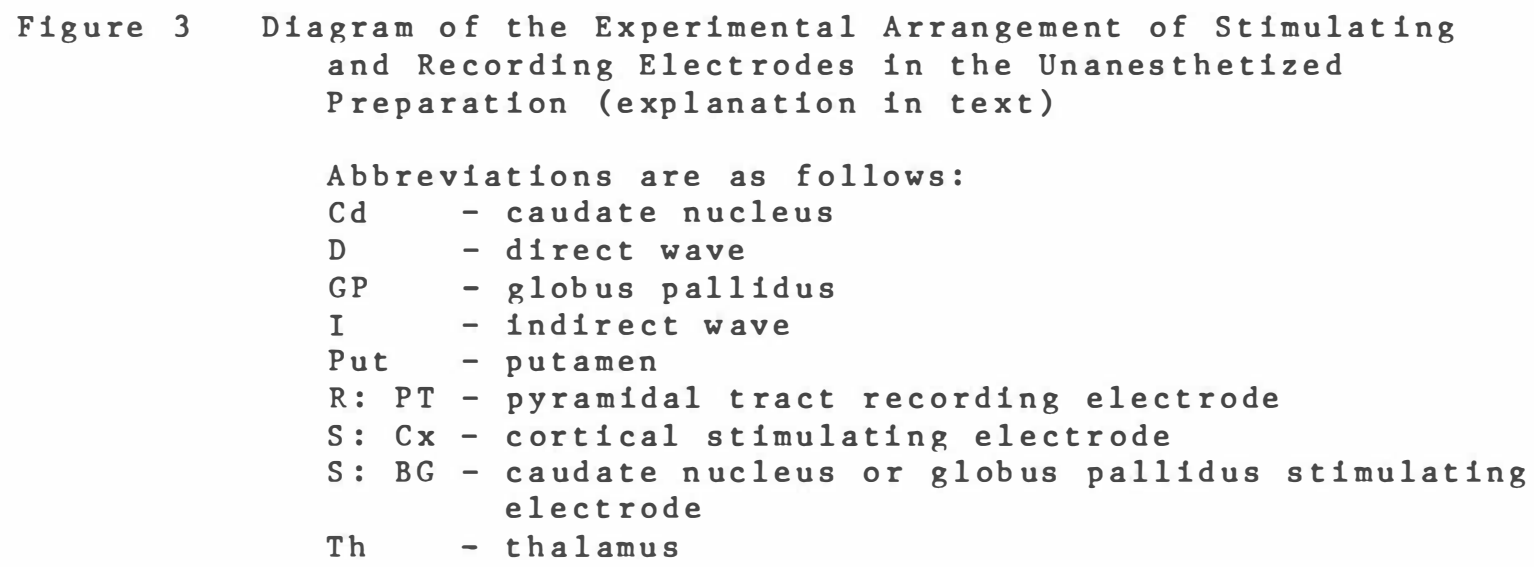




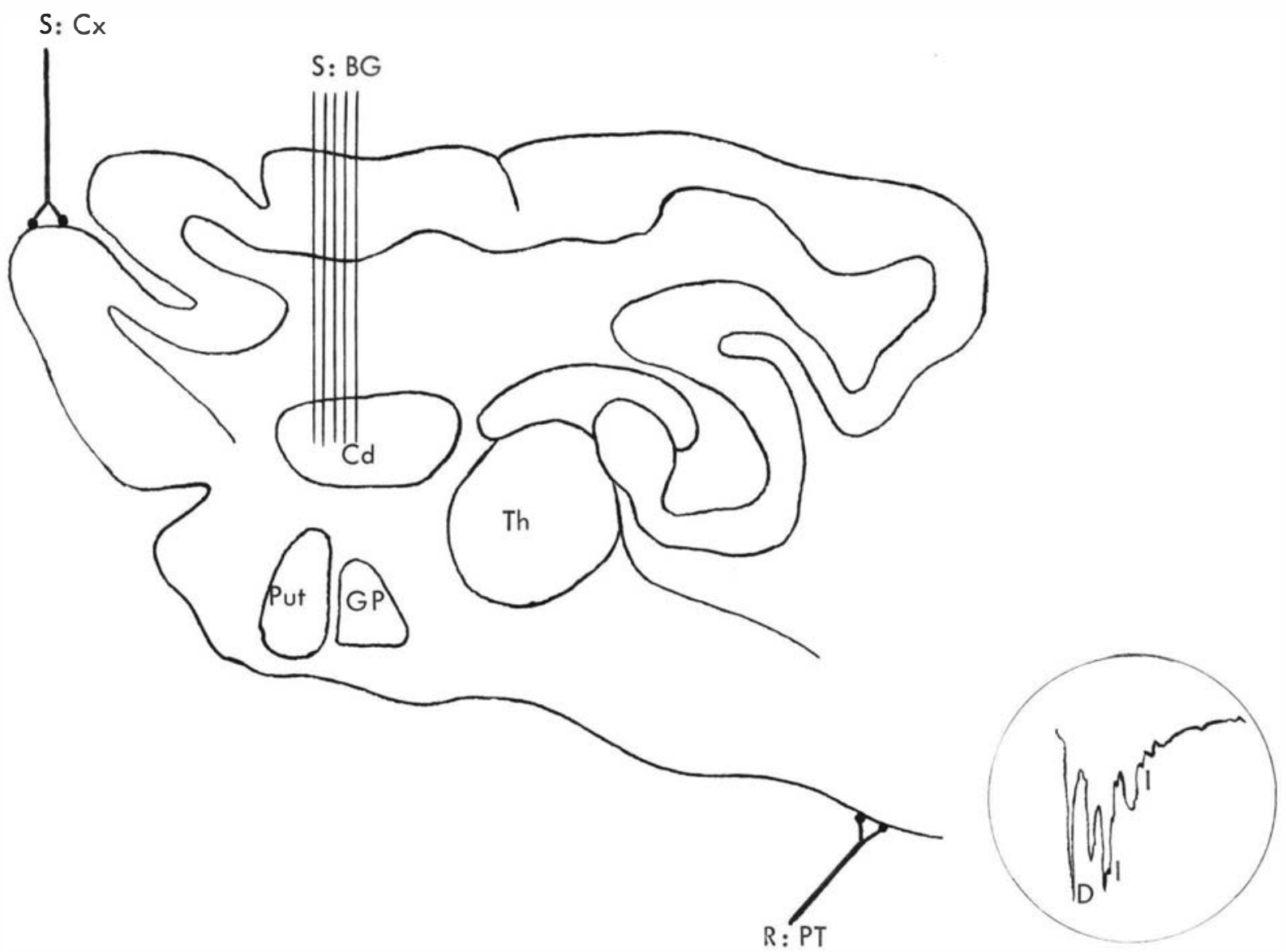


termed the test stimulus. The conditioning stimulus was a 500 msec train of pulses of 0.5 msec pulse duration with a frequency of 100 cycles per second delivered to a palr of adfacent electrodes within the "comb". Stimulus intensity was $25 \mathrm{~V}$ or $2.5 \mathrm{~mA}$. The conditioning stimulus evoked no direct response in the pyramidal tract.

Control test stimulations to the sensorimotor cortex were delivered and the D-I response recorded in the pyramidal tract was amplified, monftored on a Tektronix 5103N storage scope, and stored on magnetic tape. A conditioning-test stimulation sequence followed in which a 500 msec train of pulses delivered to a pair of electrodes within the "comb" followed by a post-stimulus shock to the cortex. For each palr of electrodes within efther the caudate nucleus or globus pallidus, a minfmum of ten control cortical responses and a minfmum of ten responses from the conditioning-test sequence were obtained. A similar format for each pair of electrodes within the "comb" was used. Following recording at a horizontal level within the subcortical structure, electrolytic lesions were produced. The "comb" was lowered one millimeter and the experimental format repeated.

3. Data Analysis

Direct and indirect (D-I) responses recorded from the pyramidal tract were monitored on a Tektronix storage oscilloscope. Representative samples of five consecutive 
sweeps from both the cortical stimulation alone and conditioning-test stimulation were photographed on Polarold black and white Land Pack f $11 \mathrm{~m}$ type 107 by a Tektron $1 x$ C-5 camera. All D-I responses recorded from the pyramidal tract were averaged on a Digital PDP Lab $8 / E$ computer. E1ght responses elicited by cortical stimulation were averaged and plotted on an X-Y plotter. This procedure was employed for averaging the responses from the conditioning-test sequence for each pair of electrodes within the "comb". Therefore, each conditioning-test sequence response could be compared with the preceeding and following averaged cortical control responses.

Loc1 were designated as "+", "-", and "0" according to whether the loci respectively facilitated, Inhibited or had no effect on cortically induced D-I responses. A locus was designated as "+" If the amplitudes of the direct and Indirect responses elicited by the conditioning-test stimulus were at least thirty per cent above the cortical control responses. Similarly, if the amplitudes of the D-I responses elicited by the conditioning-test stimulus were at least thirty per cent less than the cortical control responses, a "-" was employed to designate the locus. For those loci in which the average test response was only thirty per cent different from cortical control response, a further analysis was made in which six of the elght test responses needed to differ from control responses by more than thirty 
per cent before the locus was designated either "+" or "-". These criteria were sufficient to conclude that responses at each "+" and "-" locus were significantly different from control responses ( $p<0.01 ;$ Ch1 Square). Response variability at sites where the conditioning-test responses differed from the cortical control response by more than thirty per cent was similar to the borderifne cases and therefore the significance was obvious.

\section{Histology}

Histological verification of electrode placement within the caudate nucleus and globus pallidus for both types of preparations was made. At the end of an experiment the distal end of each carotid artery was cannulated and the brain perfused with 200 cc of physlological saline followed by 200 cc of $1.0 \%$ potassium ferricyanide in $10 \%$ formalin solution. The brain was removed and placed in a $10 \%$ formalin solution for a minimum of three days. Following infiltration, the brain was sectioned, by means of the frozen section technique, In midsaggital serial sections of 100 micra each and placed in water for mounting. Several representative sections demonstrating electrode placement were photographed. The section, used as the negative, was enlarged in a photographic enlarger and the positive print was made on Kodabromide F-5 paper. Since staining shrinks tissue, the photographic print was used to measure electrode placement (28). All sections were then stalned by a modification of 
the Nissl stain technique by Fernstrom (22) for further clarification of stimulation points. 


\section{RESULTS}

\section{A. Anesthetized Preparation \\ 1. Ia Afferent Dorsal Root Activity}

Spontaneous Ia afferent dorsal root discharge varied among the muscle spindles studied. The resting afferent discharge ranged from zero spikes per second to forty spikes per second. Resting spindle discharge referred to the occurrance of spindle discharge during which a ten gram tension was placed upon the anterior tibialis muscle. Ia afferent dorsal root activity of the anterior tibialis muscle increased when a train of electrical shocks was delivered to the sensorimotor cortex or to the bulbar pyramidal tract. Control cortical and pyramidal tract records demonstrating an increase in Ia afferent activity are shown in Figures 4 and 7 , respectively. The small spikes in Figure 4 represent afferent activity of a hip flexor. Muscles, excluding the anterior tibialis muscle, from which afferent fibers were recorded were identified by application of stretch to various areas of the hind limb. Stimulation of the cortex did not elicit an increase in the afferent activity. Lack of responsiveness of hip afferent fiber activity to cortical stimulation was noted in several preparations. However, electrical stimulation of the cortex or pyramidal tract induced changes within the gamma system (indirectly measured by Ia afferent activity) at intensities 
lower than that necessary to activate the alpha system (1ndirectly measured by EMG and myogram) of the anterior tibialis muscle. This indicated a lower threshold of the gamma system to cortical and pyramidal tract stimulation in this preparation. Increase in Ia afferent activity was a function of stimulus intensity, le, an increase in stimulus intensity elicited an increase in Ia afferent discharge. Therefore, the stimulus intensity level was adJusted in each preparation so a minimal increase in Ia afferent discharge in response to a control cortical stimulation occurred.

2. Caudate Nucleus Modulation of Cortical and Pyramidal Tract Induced Flexor Activity

Responses elicited from simultaneous stimulation of the cortex and a locus within the caudate nucleus were enhanced, diminished or did not deviate from the control cortical response. Figure 4 demonstrates inhibition of cortically Induced hind $11 \mathrm{mb}$ flexor activity. Stimulation of the cortex produced an Increase in Ia afferent dorsal root discharge of the anterior tiblalis muscle without producing measurable alpha motoneuronal activity. No increase in dorsal root discharge in the hip flexor (small spikes) occurred. Simultaneous pairing of the cortex and caudate nucleus stimulation decreased the cortically induced increase in Ia afferent activity. Electrical stimulation of the caudate nucleus alone produced no effect upon elther the Ia afferent 
Figure 4 Caudate Nucleus Modulation of a Cortically Induced Flexor Response: Inhibition

A. Stimulation of the cortex: an increase in I a afferent dorsal root activity of the anterior tiblalis muscle.

B. Stimulation of the cortex and caudate nucleus: inhibition of the cortically induced increase in Ia afferent activity.

C. Stimulation of the caudate nucleus: no increase in Ia afferent activity. 


\section{A. Cortex}

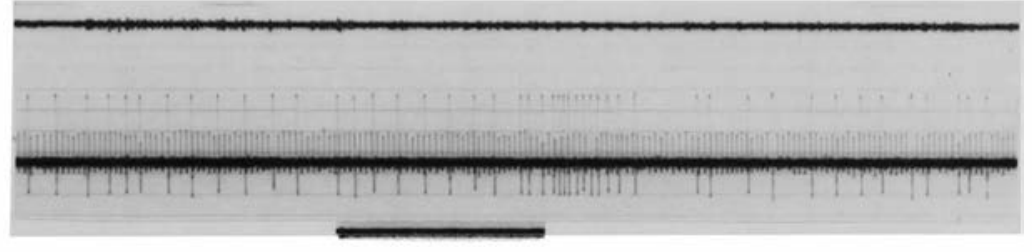

EMG

Dorsol Root

Shock Artifact

B. Cortex and Caudote Nucleus

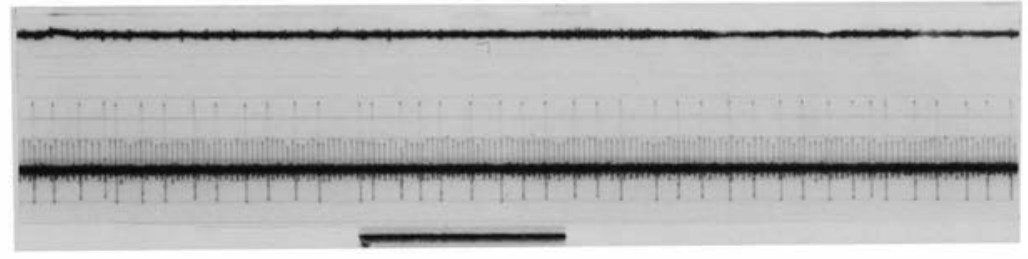

EMG

Dorsol Root

Shock Artifact

C. Caudate Nucleus

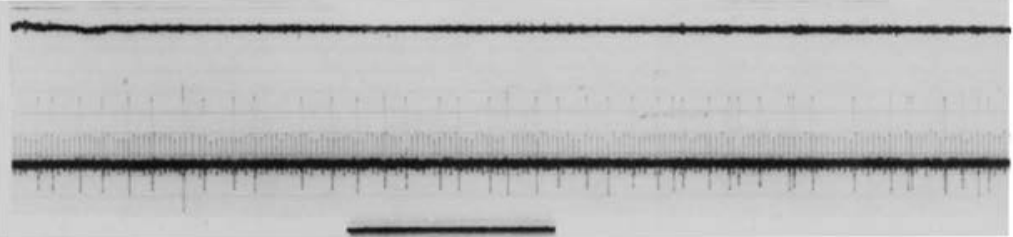

EMG

Dorsal Root

Shock Artifact 
activity of the spindle or the afferent activity of the hip flexor. The decrease or inhibition of the cortically induced increase in Ia afferent activity often occurred with stimulation of loci within the rostral region of the caudate nucleus. Increasing the stimulus intensity of some inhibitory loci enhanced cortically induced activity. The rostral portion of the caudate nucleus tended to be either inhibitory or Inactive. Ch1 square analysis $(p<0.01)$ confirmed the hypothesis that there were significantly more inhibitory loci distributed within the rostral as opposed to the caudal half of the caudate nucleus. However, rostral regions of the caudate nucleus also contained a few facilitatory loci.

When palred trains of electrical shocks were simultaneously delivered to the cortex and to some sites within the caudate nucleus, an increase in firing frequency of the Ia afferent flber occurred that exceeded the cortical control response. EMG and myogram activity also occurred in some instances as demonstrated in Figure 5 which 111 ustrates caudate nucleus facilitation of cortically induced activity. Stimulation of the caudate nucleus alone produced no effect. Caudal reglons of the caudate nucleus tended to facilitate cortically induced hind limb flexor activity. Inactive loci were also found in this region. No inhibitory loci were located in the caudal portion of the caudate nucleus. Increasing the intensity of stimulation to the caudal region of the caudate nucleus Increased these facilitatory effects upon gammactivity 
Figure 5 Caudate Nucleus Modulation of a Cortically Induced Flexor Response: Facilitation
A. Stimulation of the cortex: an increase in Ia afferent dorsal root activity of the anterior tibialis muscle.
B. Stimulation of the cortex and caudate nucleus: facilitation of Ia afferent activity, increase in myogram and EMG activity.
C. Stimulation of the caudate nucleus:
no increase in Ia afferent activity. 
A. Cortex

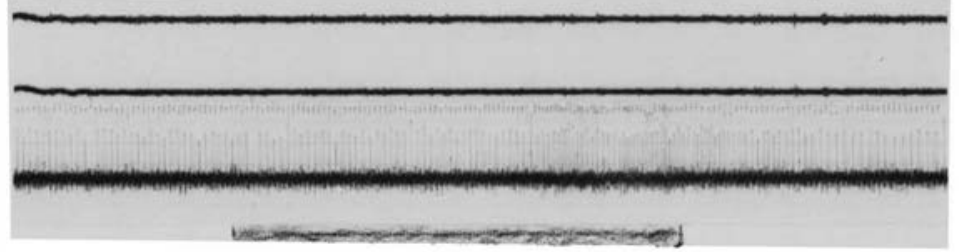

EMG

Myogram

Dorsal Root

Shock Artifact

B. Cortex and Caudate Nucleus

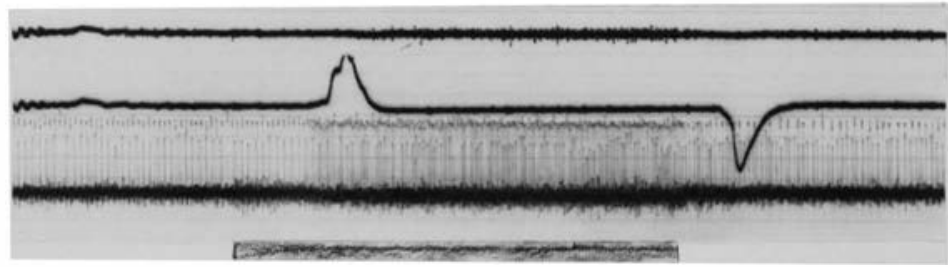

EMG

Myogram

Dorsol Root

Shock Artifact

C. Caudate Nucleus

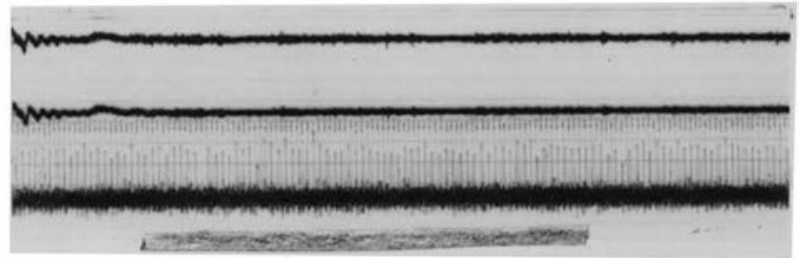

EMG

Myogram

Dorsol Root

Shock Artifact 
although no alpha activity was recorded.

Figure 6 represents on midsaggital maps the loci within the caudate nucleus that when stimulated enhanced or decreased cortically induced hind limb flexor responses. Loci that did not influence cortically induced hind limb flexor responses are also represented. Whereas facilitatory loci were scattered throughout the caudate nucleus, the inhibitory loci tended to be located in the rostral portion of this structure.

Trains of electrical shocks delivered to the bulbar pyramidal tract elicited an increase in Ia afferent discharge independent of EMG or myogram activity as demonstrated in Figure 7. Paired stimulation of the pyramidal tract and loci within the caudate nucleus produced either facilitation or no effect upon activity induced by pyramidal tract stimulation. Caudate nucleus stimulation alone produced no effects upon hind limb flexor activity. In marked contrast to the inhibitory effects of caudate nucleus stimulation on cortically induced flexor responses, caudate nucleus stimulation did not produce any inhibitory effects upon pyramidal tract induced flexor responses in these same animals. Loci within the caudate nucleus that enhanced or did not influence responses elicited by pyramidal tract stimulation are represented on midsaggital sections in Figure 8 . 
Figure 6 Loc1 within the Caudate Nucleus which Altered Cortically Induced Motor Activity in the Anesthetized Preparation

Loci indicate areas within the caudate nucleus which when stimulated enhanced ( + ), decreased (-), or had no effect (0) upon cortically induced hind $11 \mathrm{mb}$ flexor responses. Diagrams A,B,C represent sections $2.5 \mathrm{~mm}, 3.5 \mathrm{~mm}$, and $5.0 \mathrm{~mm}$ from the midline, respectively.

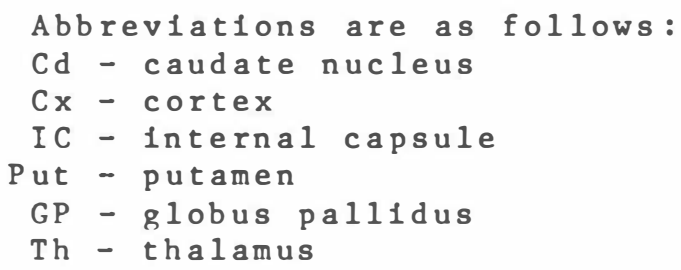



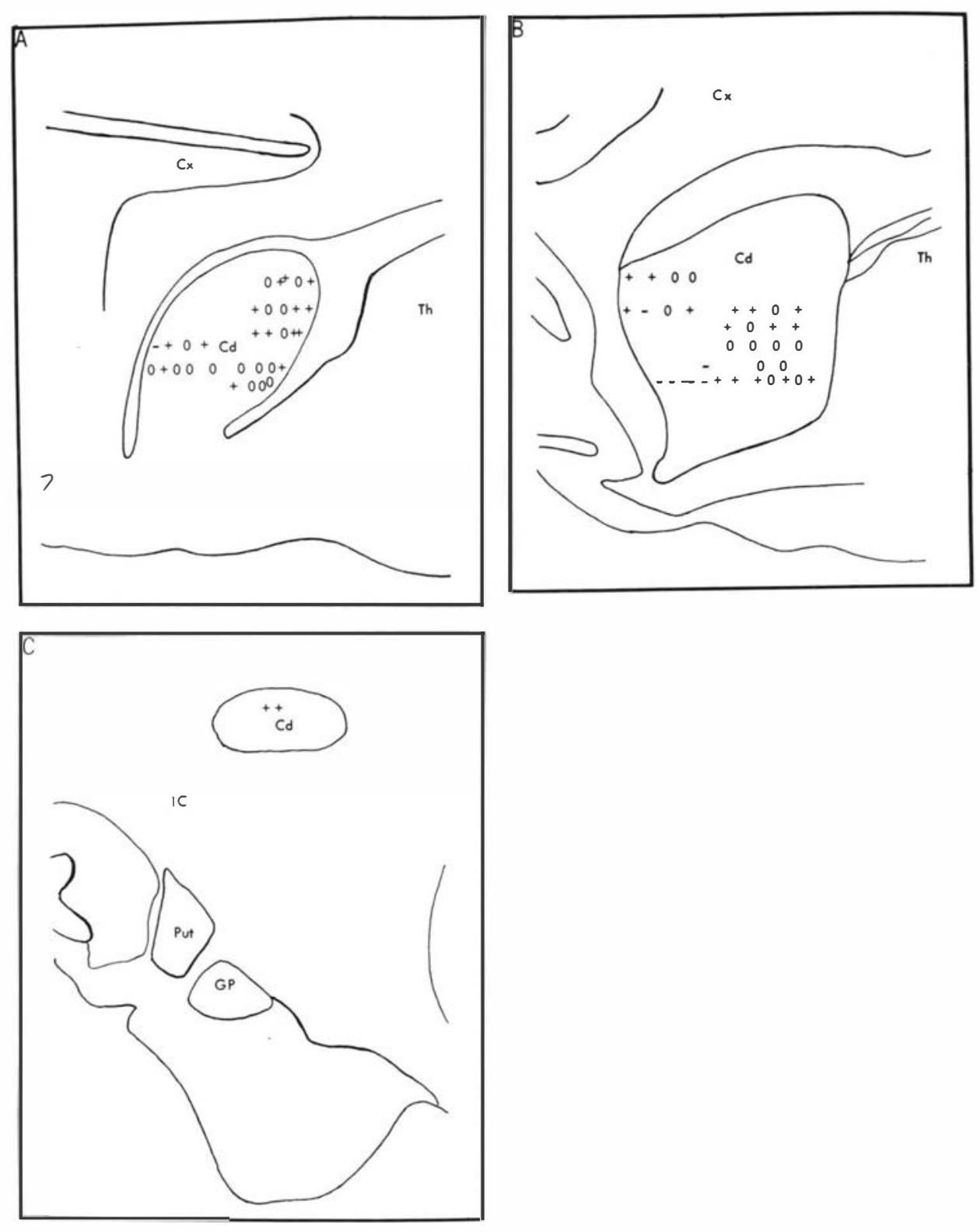
Figure 7 Caudate Nucleus Modulation of a Pyramidal Tract Induced Flexor Response: Faclitation

A. Stimulation of the pyramidal tract: an increase in $I$ a afferent dorsal root activity of the anterior tibialis muscle, myogram and EMG activity.

B. Stimulation of the pyramidal tract and caudate nucleus: an enhancement of the pyramidal tract induced increase in Ia afferent activity, myogram and EMG activity.

C. Stimulation of the caudate nucleus: no increase in Ia afferent activity, no EMG or myogram activity. 
A. Pyramidal Tract

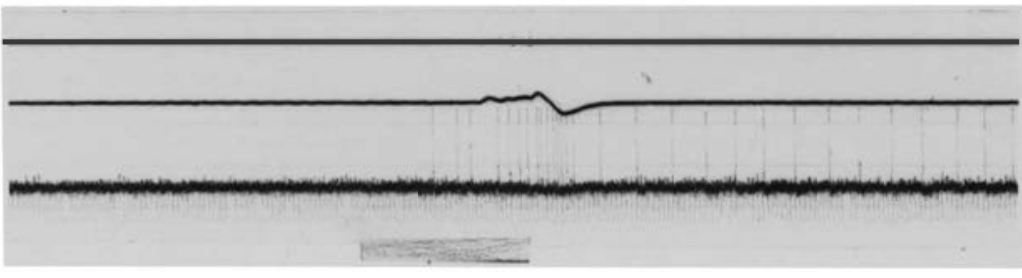

EMG

Myogram

Dorsal Root

Shock Artifact

B. Pyramidal Tract and Caudate Nucleus

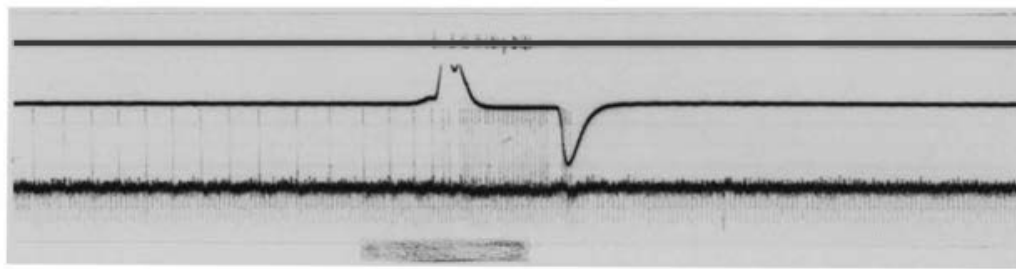

EMG

Myogram

Dorsal Root

Shock Artifact

C. Caudate Nucleus

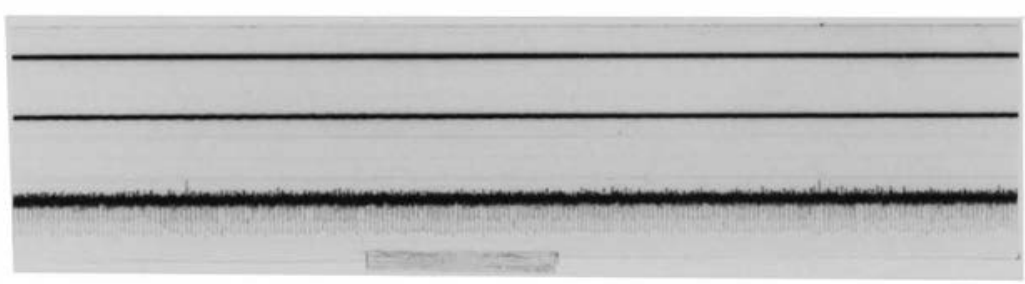

EMG

Myogram

Dorsol Root

Shock Artifact 
Figure 8 Loci within the Caudate Nucleus which Altered Pyramidal Tract Induced Motor Activity in the $\Lambda$ nesthetized Preparation

Loci indicate areas within the caudate nucleus which when stimulated enhanced ( + ), or had no effect (0) upon pyramidal tract induced hind $1 \mathrm{imb}$ flexor responses.

Diagrams $A, B, C, n$ represent sections $2.5 \mathrm{~mm}$, $3.5 \mathrm{~mm}, 5.0 \mathrm{~mm}$ and $6.0 \mathrm{~mm}$ from the midline, respectively.
Abbreviations are as follows:
Cd - caudate nucleus
$C x$ - cortex
IC - internal capsule
Put - putamen
GP - globus pallidus
Th - thalamus 

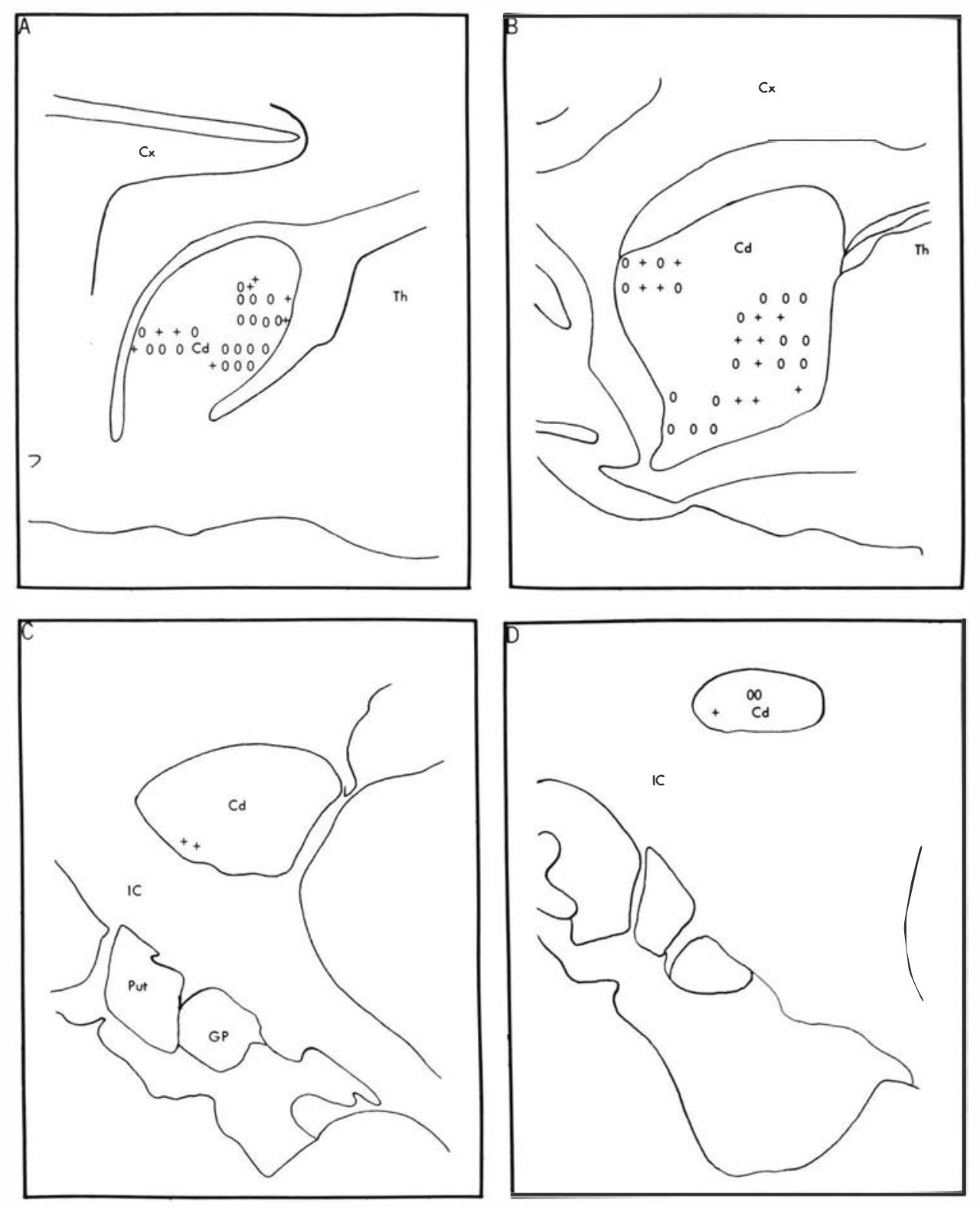
3. Globus Pallidus Modulation of Cortical and Pyramida1

Simultaneous palring of electrical shocks delivered to the cortex and a locus within the globus pallidus often produced facilitation of the cortically induced hind $11 \mathrm{mb}$ flexor response. Increases in EMG activity were also noted. Simflarly, palring of trains of shocks to the pyramidal tract and globus pallidus produced a facilitation of pyramidal tract induced flexor responses. Figures 9 and 10 demonstrate respectively the facilitation of cortical and pyramidal tract induced Ia afferent activity attributed to pallidal stimulation. Trains of electrical shocks that facilitated cortical or pyramidal tract induced flexor responses when delivered to loci within the globus pallidus did not elicit flexor responses by themselves. The loci within the globus pallidus that facilitated cortically induced or pyramidal tract induced flexor responses are represented on maps of the globus pallidus in Figure 11.

4. Internal Capsule

Influences from the Internal capsule upon cortically Induced activity served as an indicator for spread of current. Facilitatory influences upon cortically induced Ia afferent activity by internal capsule stimulation occurred as evident by an increase in Ia afferent activity and in some cases an increase in EMG activity and myogram tension. In some Instances stimulation of the internal capsule at the same 
Figure 9 Globus Pallidus Modulation of a Cortically Induced Flexor Response

A. Stimulation of the cortex: an increase in Ia afferent dorsal root activity of the anterior tiblalis muscle.

B. Stimulation of the cortex and globus pallidus: increase in Ia afferent activity, EMG activity.

C. Stimulation of the globus pallidus: no increase in Ia afferent activity. 
A. Cortex

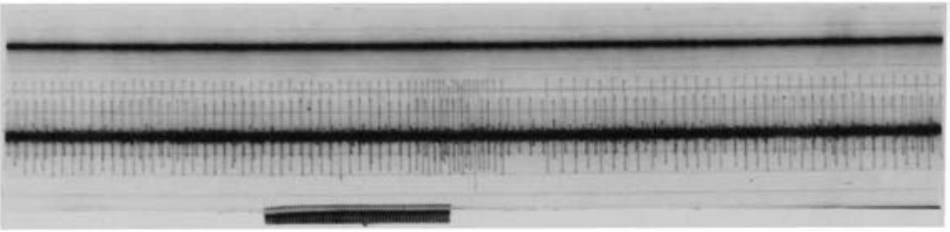

DMG

Dorsal Root

Shock Artifact

B. Cortex and Globus Pallidus

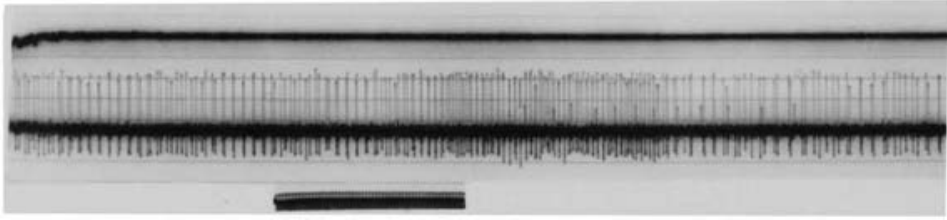

EMG

Dorsal Root

Shock Artifact

C. Globus Pallidus

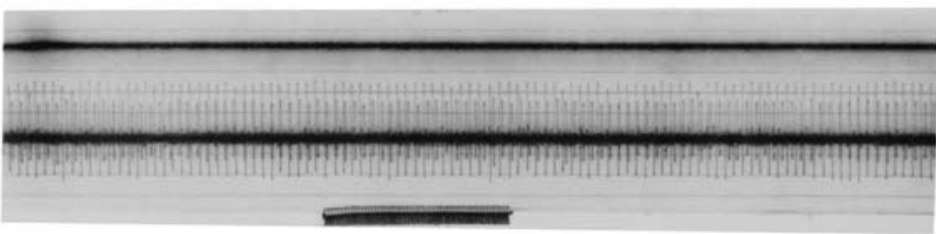

EMG

\section{Dorsal Root}

Shock Artifact 
Figure 10 Globus Pallidus Modulation of a Pyramidal Tract Induced Flexor Response
A. Stimulation of the pyramidal tract: increase in Ia afferent dorsal root activity of the anterior tiblalis muscle.
B. Stimulation of the pyramidal tract and globus palifdus: increase in Ia afferent activity.
C. Stimulation of the globus pallidus: no increase in Ia afferent activity.


A. Pyramidal Tract

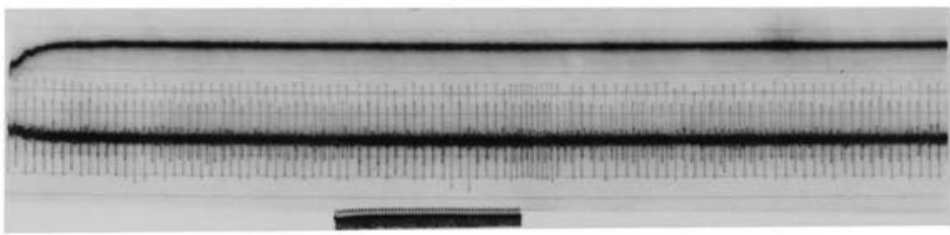

EMG

Dorsal Root

Shock Artifact

B. Pyramidal Tract and Globus Pallidus

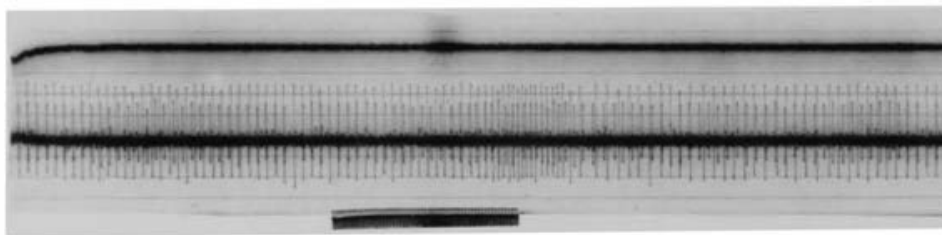

EMG

Dorsal Root

Shock Artifact

C. Globus Pallidus

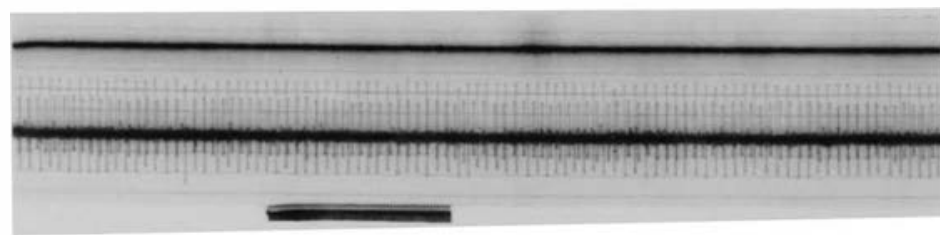

EMG

Dorsal Root

Shock Artifact

$1.0 \mathrm{sec}$ 
Figure 11 Loc1 within the Globus Pallidus which Altered Cortically Induced and Pyramidal Tract Induced Motor Responses

A. Loc1 indicate areas within the globus pallidus which when stimulated enhanced $(+)$, or had no influence (0) upon cortically induced hind $11 \mathrm{mb}$ flexor response.

B. Loc1 indicate areas within the globus pallidus which when stimulated enhanced $(+)$, or had no influence (0) upon cortically induced hind $11 \mathrm{mb}$ flexor response.

Both represent sections $8.0 \mathrm{~mm}$ from the midline.

Abbreviations are as follows: $G P$ - globus pallidus IC - Internal capsule Put - putamen 

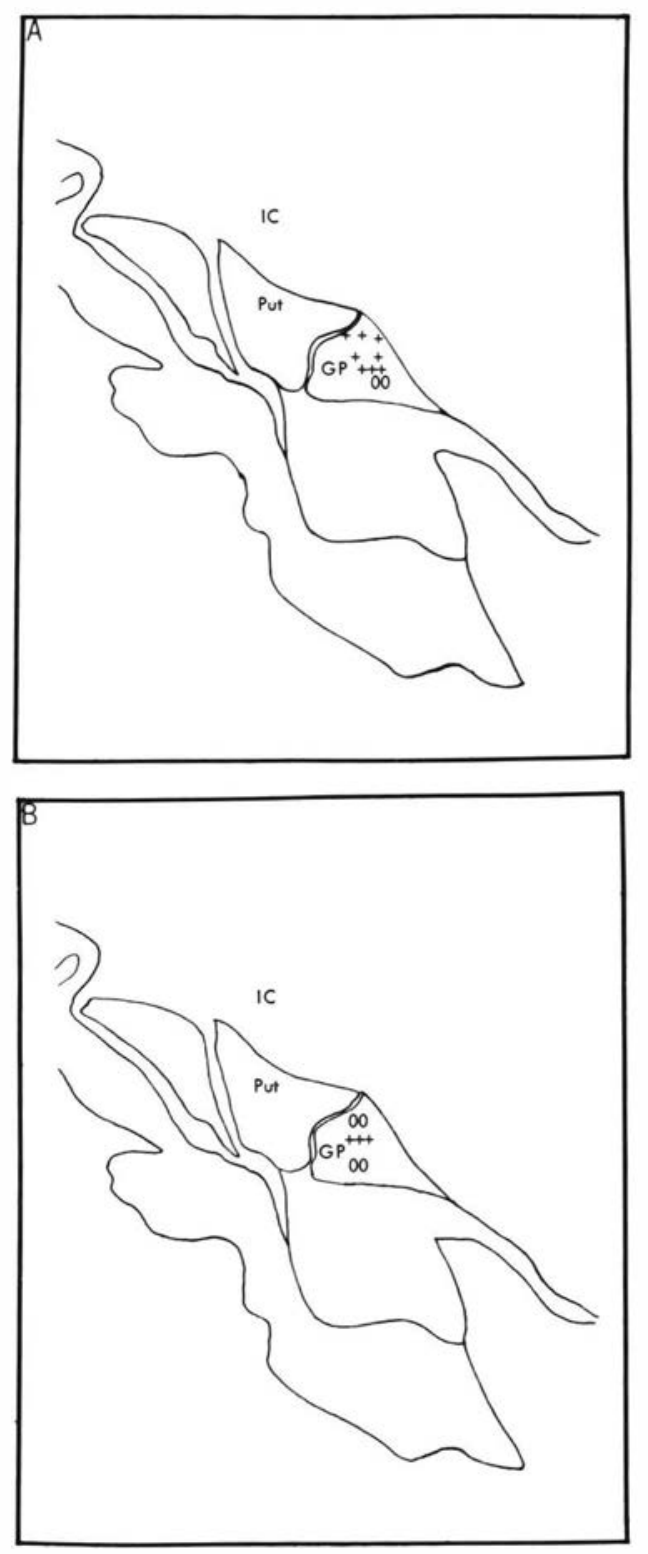
Intensity as that for the caudate nucleus produced greater facilitatory effects upon cortically induced hind $11 \mathrm{mb}$ flexor responses. When the internal capsule was stimulated alone, an increase in Ia afferent discharge occurred, a result unlike that found for the caudate nucleus or globus pallidus. However, since no further differentiation between effects of the caudate nucleus and Internal capsule was evident, loc1 bordering the caudate nucleus and internal capsule were omftted from the study. In one decorticate preparation, a long latency and prolonged facilitation of pyramidal tract induced afferent activity was observed with palred pyramidal tract-caudate nucleus stimulation, whereas an Immediate increase in pyramidal tract induced activity was noted with simultaneous stimulation of the internal capsule and pyramidal tract.

\section{Decorticate Preparation}

Four cats were decorticated in order to eliminate the caudate nucleus circult to the cortex via the thalamus. Experimental recordings were made one and one-half hours to two hours following decortication. Purpura (67) confirmed the functional integrity of caudate nucleus cells two hours following cortical ablation rostral to the caudate nucleus. Stimulation of the pyramidal tract resulted in an increase in Ia afferent activity at stimulus intensities that corresponded to those employed in the intact preparation. Simultaneous pairing of pyramidal tract and caudate nucleus stimulation 
in three of the four cats resulted in either an increase or prolonged facilitation of Ia afferent activity, thereby indicating the functional integrity of the caudate nucleus. Caudate nucleus stimulation alone produced no changes in Ia afferent activity as demonstrated in Figure 12.

Figure 13 represents on midsaggital sections of the cat brain the distribution of loci stimulated within the caudate nucleus that enhanced or produced no effect upon hind limb flexor responses elicited by stimulation of the pyramidal tract in the decorticate preparation. No inhibition of induced pyramidal tract activity attributed to caudate nucleus stimulation occurred in the rostral portion of the caudate nucleus. Inactive points were recorded throughout the caudate nucleus.

B. Unanesthetized Preparation

Experiments were performed in an unanesthetized preparation to determine how cortically evoked responses in the bulbar pyramidal tract could be modulated by shock trains delivered to selected sites within the basal ganglia. A single shock delivered to the sensorimotor cortex evoked in the ipsilateral bulbar pyramidal tract a positive deflection with a latency of approximately $0.7 \mathrm{msec}$. Generally one, but in some cases a series of positive deflections followed the first deflection. Latency for the onset of the second wave was generally 2.0 to $3.0 \mathrm{msec}$. 
Figure 12 Caudate Nucleus Modulation of a Pyramidal Tract Induced Flexor Response in the Decorticate Cat

A. Stimulation of the pyramidal tract: increase in Ia afferent dorsal root activity of the anterior tiblalis muscle.

B. St1mulation of the pyramidal tract and caudate nucleus: increase in Ia afferent activity.

C. Stimulation of the caudate nucleus: no increase in Ia afferent activity. 
A. Pyramidal Tract

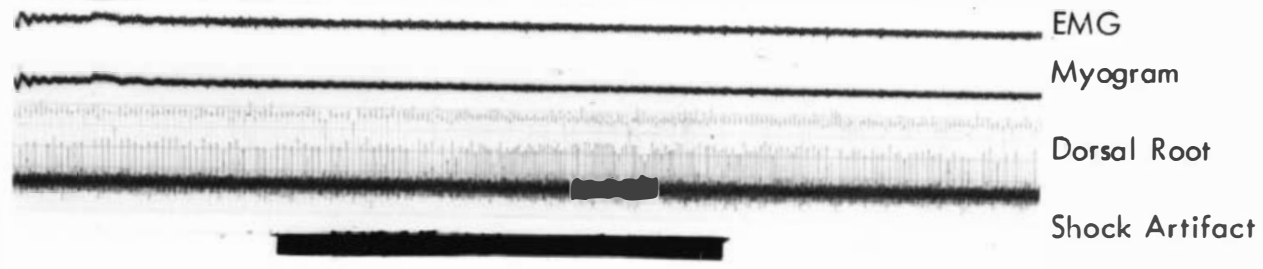

B. Pyramido I Tract and Caudote Nucleus

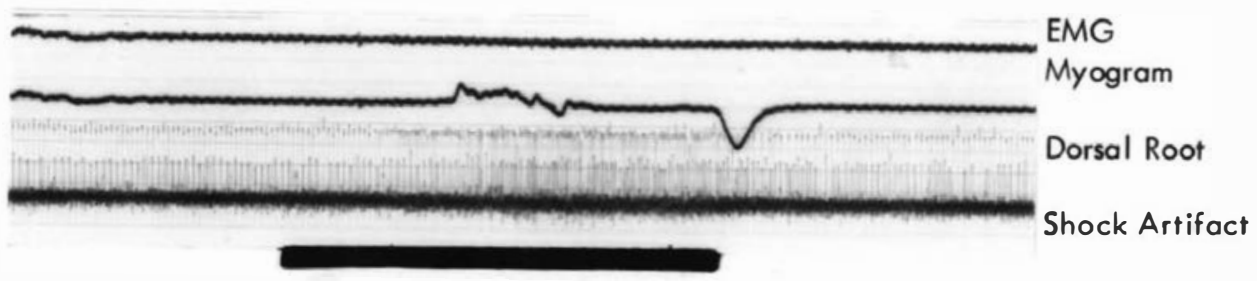

C. Caudote Nucleus

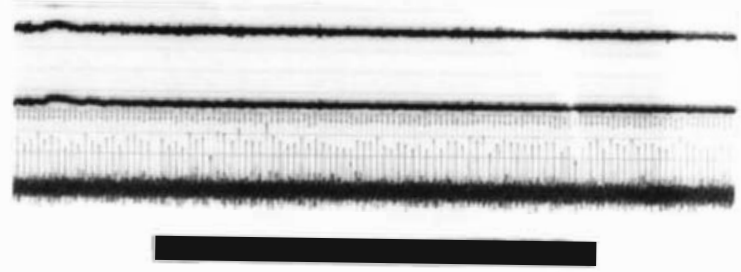

EMG

Myogram

Dorsal Root

Shock Artifact

$1.0 \mathrm{sec}$ 
Figure 13 Loc1 within the Caudate Nucleus which Altered Pyramidal Tract Responses in the Decorticate Preparation

Loc1 Indfcate areas within the caudate nucleus which when $s t 1 m u l a t e d$ enhanced $(+)$, or had no effect (0) upon pyramidal tract induced hind $11 \mathrm{mb}$ flexor responses in the decorticate preparation.

Diagrams A, B, C represent sections $2.5 \mathrm{~mm}, 3.5 \mathrm{~mm}$, and $5.0 \mathrm{~mm}$ from the m1dline, respectively.

Abbreviations are as follows:

Cd - caudate nucleus

Cx - cortex

GP - globus pall1dus

IC - Internal capsule

Put - putamen

Th - thalamus 

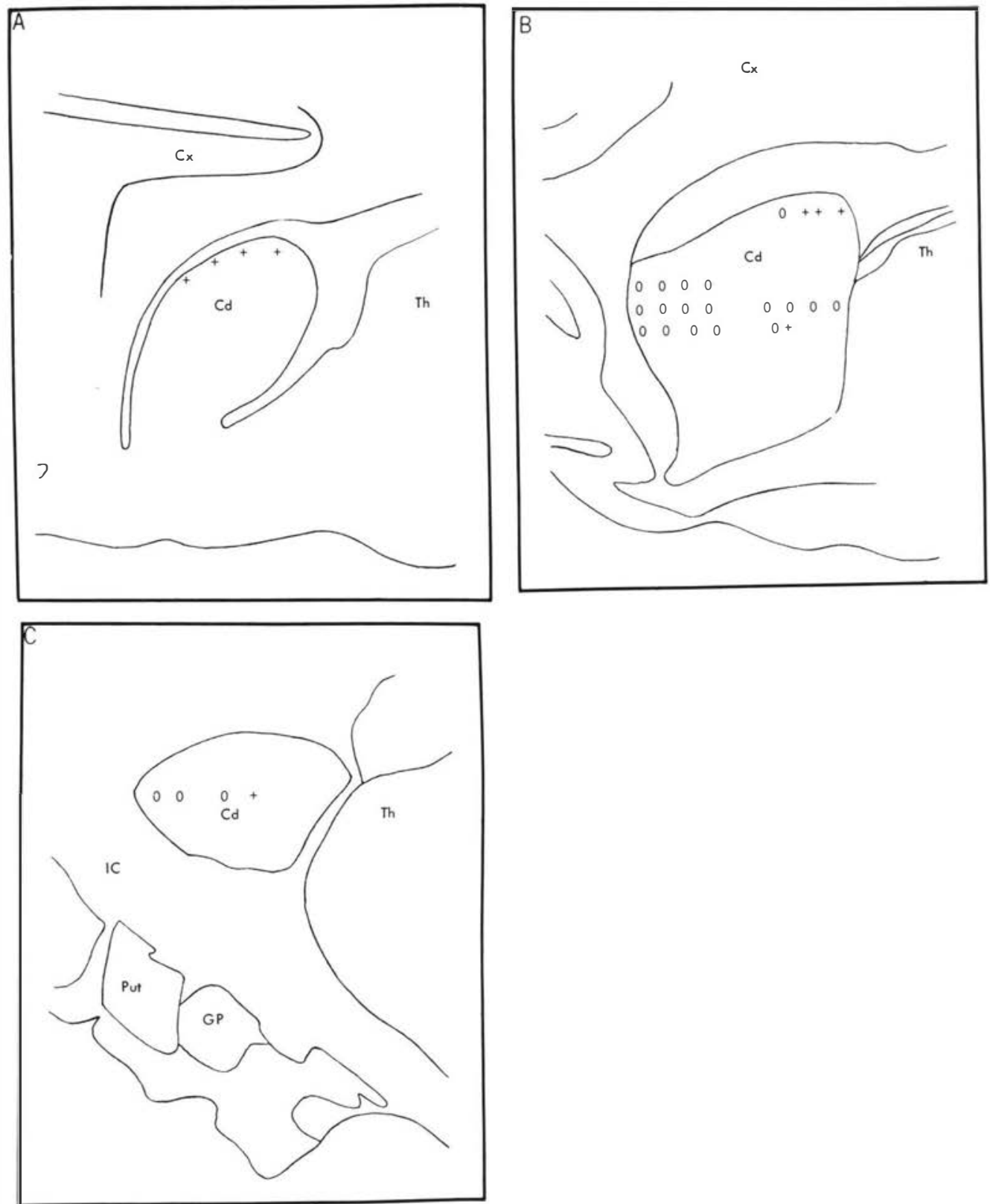
The first positive deflection shall be termed the D or direct wave since it is well established that it results from direct stimulation of pyramidal tract cells (64). The series of positive deflections occurring at 2.0 to $2.5 \mathrm{msec}$ intervals shall be termed indirect responses or I waves which follow the direct response. These indirect waves result from stimulation of pyramidal tract cells via synaptic activation as well as from stimulation of slower conducting pyramidal tract fibers (64). Figure 14 demonstrates the changes in D-I responses at various depths within the cerebral cortex. A single shock of 12.0 volts (1.2 mA) and a pulse duration of $0.1 \mathrm{msec}$ was delivered to the cortex and the evoked D-I responses were recorded In the bulbar pyramidal tract. The I wave reached a maximum amplitude at a depth of approximately $2.0 \mathrm{~mm}$ below the cortical surface. As the electrode descended, the I wave decreased until it disappeared at $4.0 \mathrm{~mm}$ below the cortical surface at a point at which synaptic activation of cortical cells would be unlikely. The amplitude of the D wave decreased deep within the cortical white matter which indicated the range was exceeded for direct activation of cortical cells. The intensity of cortical stimulation also modified the amplitude of the cortically evoked D-I responses. Various intensities were applied to the sensorimotor cortex in order to elicit the minfmum and maximum D-I responses 
Figure 14 Changes in Amplitude of the Direct and Indirect Responses Recorded in the Pyramidal Tract. Responses Ellcited by a Single Shock Delivered to the Cortex at Various Cortical Depths. 


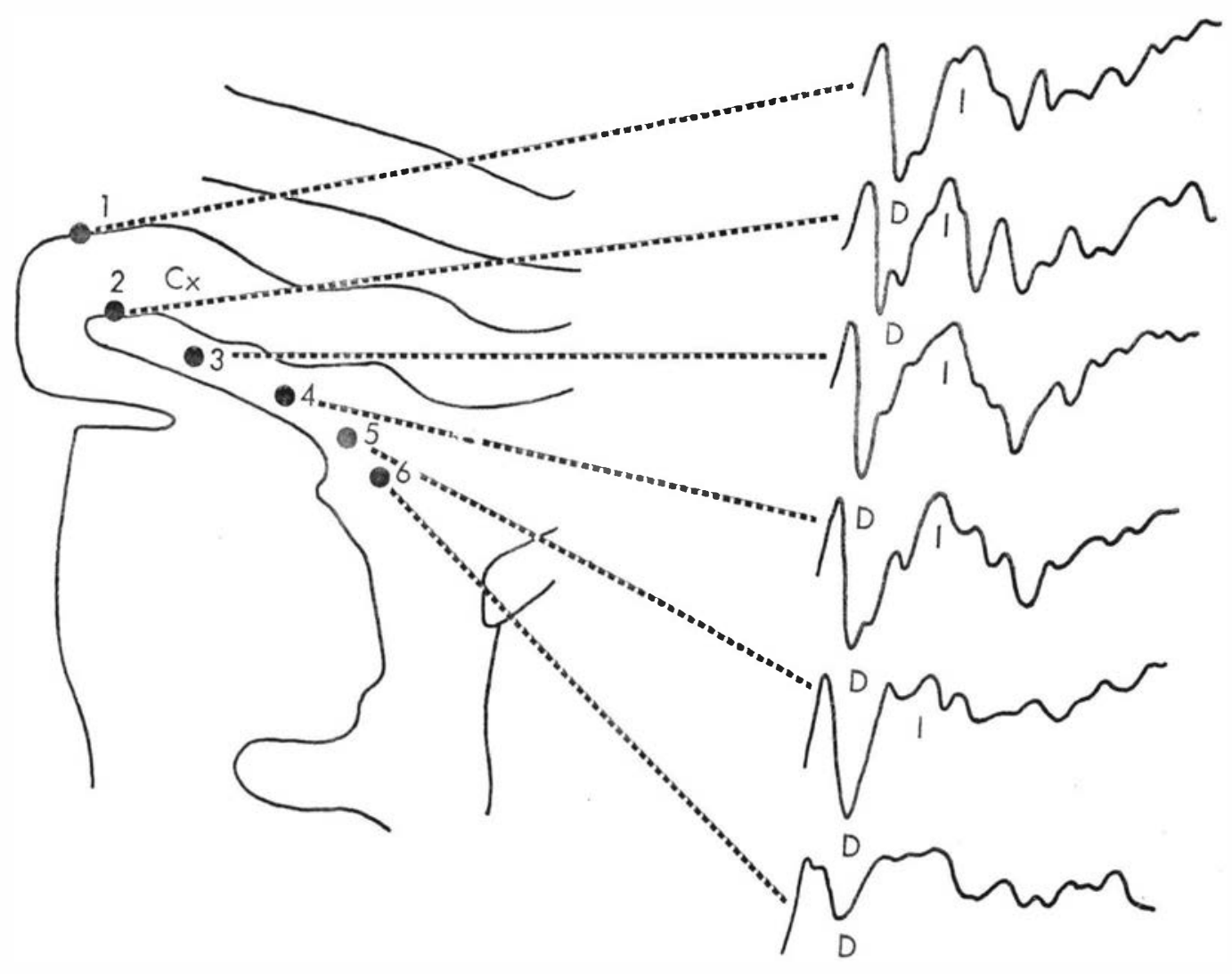

$\underbrace{}_{1.0 \mathrm{msec}} 1.0 \mathrm{~V}$ 
as indicated in Figure 15 .

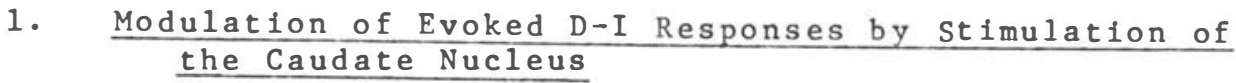
D-I responses recorded in the ipsilateral bulbar pyramidal tract and evoked by conditioning-test stimulation were enhanced, decreased or did not deviate from the control cortical evoked response. Figure 16 demonstrates average cortical control D-I responses and averaged conditioningtest D-I responses in which a decrease in amplitude of the responses occurred as a result of the caudate conditioning train. An enhancement of cortically evoked D-I responses induced by stimulation of another locus in the caudate nucleus is illustrated in Figure 17. Loci within the caudate nucleus which when stimulated decreased the amplitude of the D-I responses were distributed toward the rostral portion of this subcortical structure. Chi square analysis $(p<0.01)$ confirmed the hypothesis that there were significantly more inhibitory loci distributed within the rostral as opposed the caudal half of the caudate nucleus. However, some facilitatory loci as well as inactive points were also located in this region. Loci within the caudal portion of the caudate nucleus either facilitated the cortical responses or had no influence upon the cortical induced activity. In every case, stimulation of the caudate nucleus alone evoked no response in the bulbar pyramidal tract. Loci within the caudate nucleus that were employed in this 
Figure 15 Variation in Direct and Indirect Responses Recorded In the Pyramidal Tract due to Increasing Intensities of Cortical Stimulation 
$7.0 \mathrm{~V}, 0.1 \mathrm{msec}$

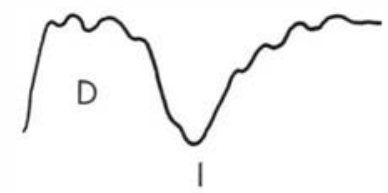

$10.0 \mathrm{~V}, 0.1 \mathrm{msec}$

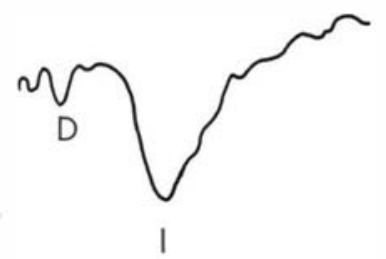

$15.0 \mathrm{~V}, 0.1 \mathrm{msec}$
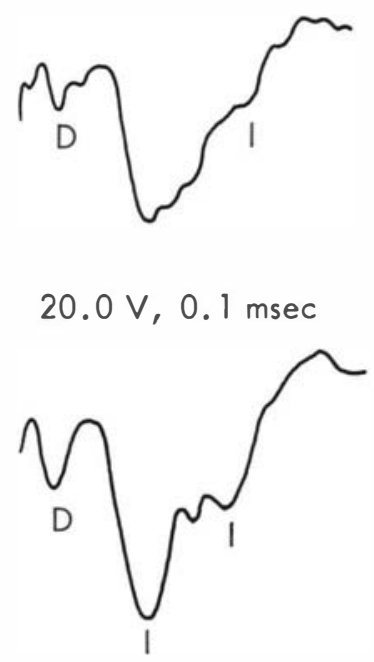

$$
\underbrace{}_{1.0 \mathrm{msec}} 1.0 \mathrm{~V}
$$


Figure 16 Modulation of Cortically Induced D-I Responses by Caudate Nucleus Stimulation: Inh1bition
A. Cortical Control Response: D-I responses.
B. Conditioning-Test Response: decrease in D-I responses.
C. Caudate Nucleus: no response recorded in the pyramidal tract. 


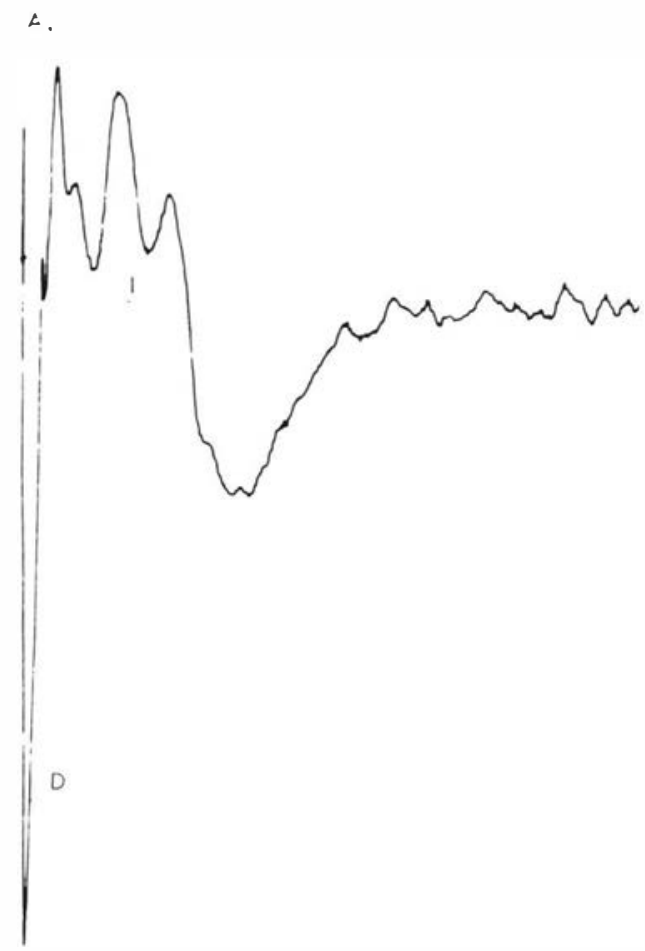

s.

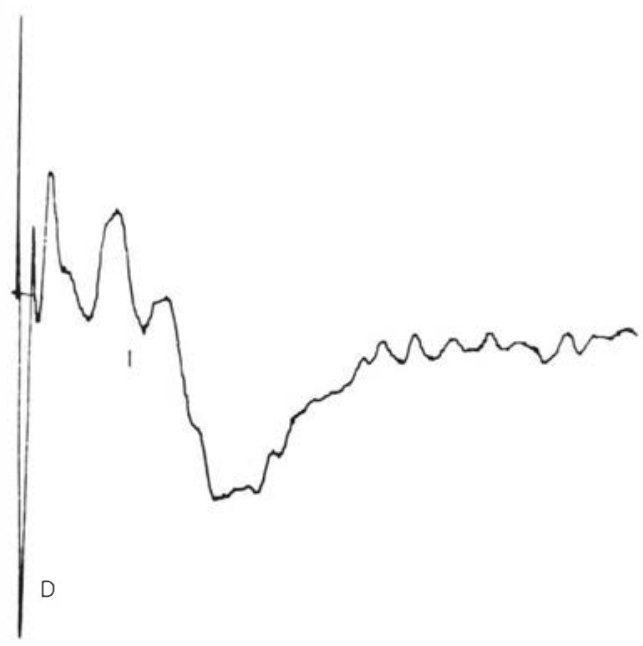

c.

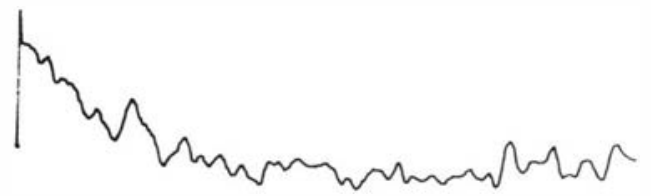

$1 . \overline{\mathrm{msec}}$ 
Figure 17 Modulation of Cortically Induced D-I Responses by Caudate Nucleus Stimulation: Facilitation

A. Cortical Control Response: D-I responses.

B. Conditioning-Test Response: increase in D-I responses.

C. Caudate Nucleus: no response recorded in pyramidal tract. 
A.

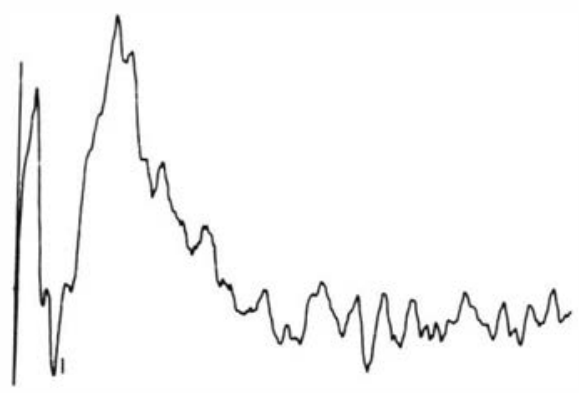

B.

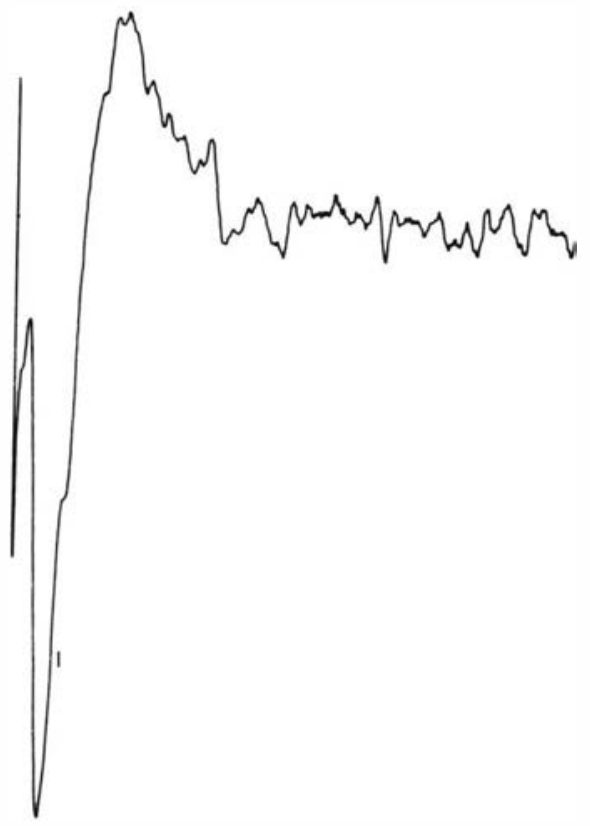

c.

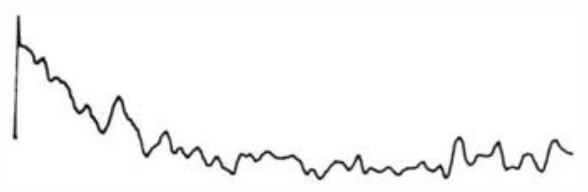

$1 . \overline{\mathrm{msec}}$ 
preparation are recorded on midsaggital sections of the cat brain in Figure 18.

2. Globus Pallidus Modulation of D-I Responses

Three loci stimulated within the globus pallidus produced efther enhancement (two loc1) or no effect (one locus) upon D-I responses eliclted by cortical stimulation. Stimulation of loci within this structure did not evoke a response in the pyramidal tract. Structures surrounding the globus pallidus and those loci bordering the internal capsule were omfted from the data. 
Figure 18 Loc1 within the Caudate Nucleus which Altered Cortical Induced D-I Responses In the Unanesthetized Preparation

Locl indicate areas within the caudate nucleus which when stimulated enhanced $(+)$, decreased (-), or had no influence (0) upon cortically elicited direct and indirect responses.

Diagrams $A, B, C$ represent sections $2.5 \mathrm{~mm}, 3.5 \mathrm{~mm}$, and $5.0 \mathrm{~mm}$ from the midline, respectively.
Abbreviations are as follows:
Cd - caudate nucleus
GP - globus pallidus
IC - Internal capsule
Put - putamen
Th - thalamus 

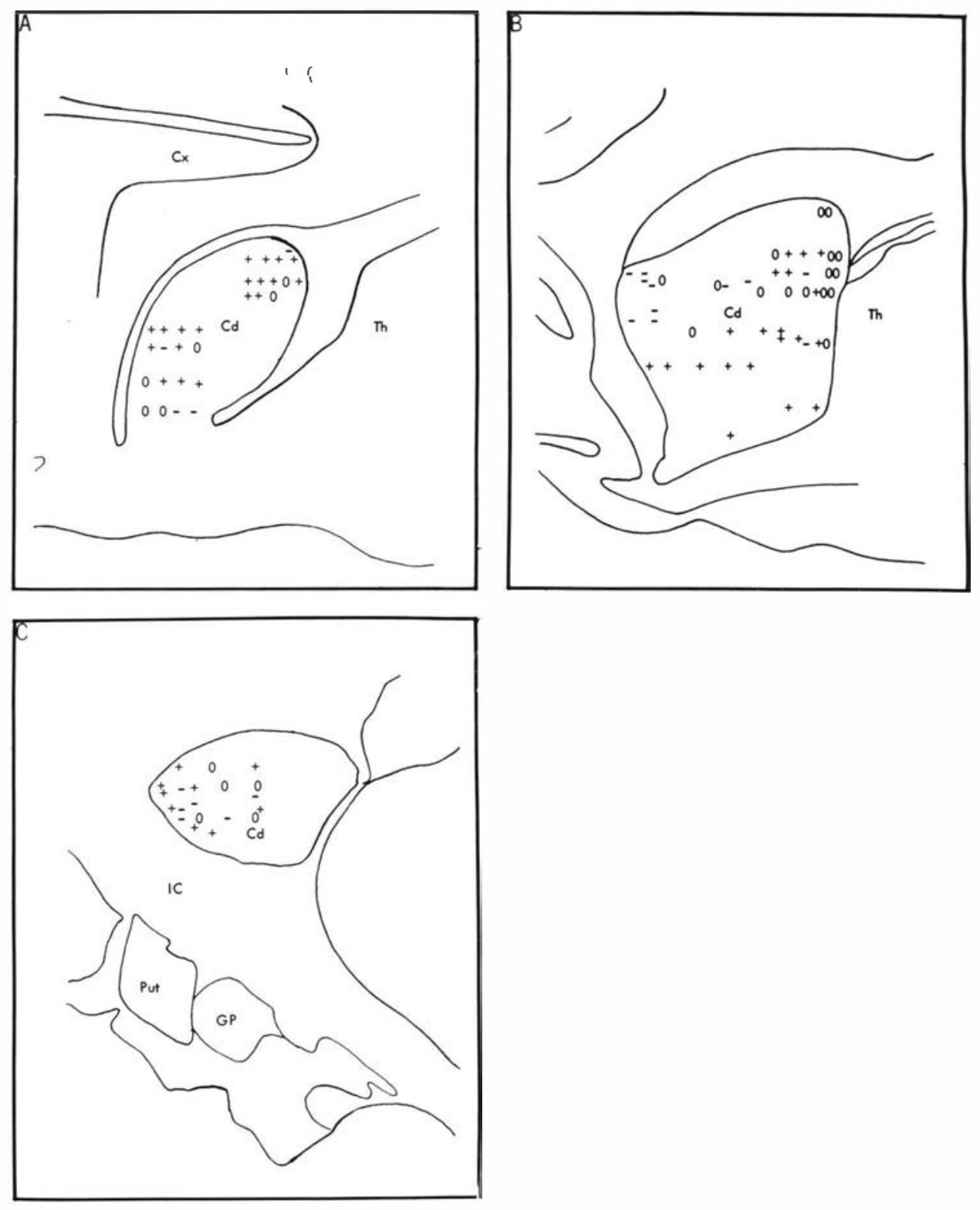


\section{DISCUSSION}

The circultry of the basal ganglia provides a bidirectional mechanism for the modulation of movement and posture. (1) The basal ganglia influence cortical motor systems; and (2) the basal ganglia exert direct influences upon subcortical levels. The ultimate location of the modulatory influences of the basal ganglia occurs at the spinal level where the final integration of motoneuronal output occurs. The present study has attempted to further clarify the contribution of these two mechanisms as to the ultimate control of motoneuronal output. Results from the anesthetized preparation provided evidence for both inhibitory and facilitatory modulation of motor activity by the basal ganglia. The levels at which these modulating effects were exerted were further clarifed in an unanesthetized preparation by investigating the influences of basal ganglia stimulation upon cortically induced responses within the pyramidal tract. Results from these two experimental approaches will be discussed and w11l be related to avallable literature.

A. Anesthetized Preparation

1. Supraspinal Regulation of Ia Afferent Activity

In the present study, stimulation of central nervous system structures such as the sensorimotor cortex, pyramidal tract and caudate nucleus activated the gamma motoneuronal system (monitored by Ia afferent activity) without simultaneous 
activation of the alpha motoneuronal system (monitored by EMG and myogram). In many cases, facilitation of tonic Ia afferent activity due to repetitive stimulation of a cortical structure outlasted the duration of stimulation. The spinal cord internuncial pool with many synaptic connections Impinging upon the gamma system could account for prolonged facilitation of the gamma system following termination of stimulation to the central structure. A clear indication that the enhancement of Ia afferent activity was due to central stimulation was the elimination of the silent period during the rising phase of contraction. Normally, a silent period of Ia afferent flbers occurs during a reflex muscle contraction when the spindle is unloaded. However, supraspinal influences Impinging upon the spinal level activate. gamma motoneurons which result in maintenance in the tension of the muscle spindle. Therefore, during this increase in gamma activity, the silent period exhiblted during the rising phase of twitch contraction is absent.

Central influences upon the gamma system werefirst Investigated by Granit and Kaada (26). Spontaneous discharge of Ia afferent fibers could be accelerated or diminished by electrical stimulation of various central structures, including the cerebral cortex, pyramidal tract, reticular formation and rostral portion of the caudate nucleus. Fac1l1tation of Ia afferent activity was more easily elicited 
from the reticular formation and the caudate nucleus regions than was elicited from the cortex. These results contrast with those of the present study in which enhancement of tonic Ia afferent activity was more easily elicited by electrical stimulation of the motor cortex and pyramidal tract. The location of the stimulating electrode in the precruclate gyrus and stimulus parameters may account for this difference. For example, Granit and Kaada (26) employed an electrical shock with a 1-2 msec duration and a frequency of 46 cycles per second, whereas a shock of 60 cycles per second and a 1.0 msec duration delivered to the cortex or pyramidal tract was employed in the present study and has been proven a more effective means for activating the gama system (55). Granit and Kaada simultaneously recorded alpha and gamma discharges and demonstrated that in the anesthetized preparation electrical currents could be selectively employed so that only activation of the gamma motoneurons occurred. The absence of co-activation of the alpha and gamma system may result from anesthetic levels or from lower recruitment thresholds for gamma motoneurons.

Granit and Kaada found that stimulation of rostral and medial regions of the caudate nucleus produced facilitatory effects upon Ia afferent discharge (26). In the present profect, the intensity of the trains of electrical shocks delivered to the caudate nucleus was adjusted so that these trains would not alter Ia afferent activity by themselves. 
It was noted that a further increase in stimulus intensity to the caudate nucleus or globus pallidus produced an enhancement of Ia afferent activity. This phenomenon was elicited by a number of loci throughout the caudate nucleus, a result similar to that observed by others (50). In the present study, only facllitation, never inhibition, of flexor muscle Ia afferent activity was elicited by electrical stimulation of the sensorimotor cortex, pyramidal tract, or caudate nucleus (at intensities greater than forty volts). When Shimazu, et al. (62), stimulated the caudate nucleus, they often obtalned both inhibition of ankle extensor muscle spindle discharge and reciprocal facilitation of flexor muscle spindle discharge. However, variable influences occurred in their preparation in which a moderate amount of anesthetic (nembutal, $15-25 \mathrm{mg} / \mathrm{kg}$ ) was administered. A weak stimulus intensity ( 4 volts) facilitated muscle spindle activity of both flexor and extensor muscles of the ankle, whereas a stronger stimulus intensity ( 6 volts) elicited a reciprocal response, le, facilitation of flexor muscle spindle discharge and inhibition of extensor muscle spindle discharge. As the depth of anesthesia increased, only reciprocal influences upon Ia afferent activity of these same muscles were elicited with electrical stimulation. These researchers postulated the existance of two descending pathways from the caudate nucleus. The first was considered a tonic, diffuse system which in- 
fluenced both extensor and flexor gamma motoneuronal systems In a similar manner and the second system was thought to be a reciprocal system. Thus, the results presented by Shimazu and co-workers do not contradict those of the present study, but rather extend them by demonstrating that reciprocal Inhibition of extensor spindle discharge also results from caudate nucleus stimulation.

2. Facilitatory and Inhibitory Modulating Influences of Evidence was presented above that stimulation of efther the caudate nucleus or globus pallidus by themselves activate central mechanisms involved in the regulation of gamma activity. That the basal ganglia are involved in the regulation of motor output of other cortical and subcortical structures was further confirmed in the present study by using a conditioning-test paradigm. Of particular importance In these experiments was the adfustment of the stimulus Intensity to the caudate nucleus or globus pallidus so that stimulation of these structures alone produced no flexor responses. Stimulation of the sensorimotor cortex enhanced Ia afferent discharge. Simultaneous stimulation of the cortex and a locus within the caudal portion of the caudate nucleus usually resulted in an enhancement of a cortically induced increase in Ia afferent discharge and in some cases activated the alpha motoneuronal system as was evident by EMG activity and myogram activity. Fac1litatory points 
were scattered throughout the caudate nucleus, a result different from that of Liles and Davis (50). They presented data that facilitatory effects upon a cortically induced response (measured by myogram tension) were located exclusively In the posterodorsal region of the caudate nucleus.

Stimulation of some rostral sites within the caudate nucleus in confuncture with cortical stimulation elicited a reduction or cessation of cortically induced gama activity. In some cases the maximal and minimal stimulus intensity for eliciting inhibition of cortically induced activity by stimulation of the cortex was obtained. For example, the minfmal intensity for eliciting a decrease in cortically induced Ia afferent discharge was 12 volts $(1.2 \mathrm{~mA})$. As the intensity of the stimulus to the caudate nucleus increased, the decrease in cortically induced activity was more pronounced until a complete inhibition of cortically induced activity occurred at 30 volts $(3.0 \mathrm{~mA})$. Stimulus intensities of 40 volts enhanced the cortically induced increase in Ia afferent discharge. Liles and Davis (50) noted similar results and attributed the phenomenon described above as spread of current to facilitatory areas of the caudate nucleus. Inhibltory areas within the caudate nucleus tended to be concentrated in the rostral portion of the caudate nucleus, whereas those loci associated with facllitation were scattered throughout the structure (See figure6). In the present study, the concentration of inhibitory loci 
toward the rostral half of the caudate nucleus was statistically significant in both the intact, anesthetized preparation and the unanethetized preparation, and $1 \mathrm{~s}$ similar to the evidence presented by Liles and Davis for caudate nucleus influences upon the alpha motoneuronal system (50). Simultaneous stimulation of the pyramidal tract and loc1 within efther the anterior or posterior regions of the caudate nucleus often resulted in increases in pyramidal tract Induced flexor responses. All caudate nucleus loci that were studied elther facllitated pyramidal tract induced responses, or had no effect; no inhibitory loci were observed. Combining these results with those concerning cortically induced responses, one can formulate the following interpretation. With respect to excltatory influences of the pyramidal motor system on flexor responses, the caudate nucleus does not inhibit these influences within the spinal cord itself. On the other hand, caudate nucleus facilitation of pyramidal tract induced flexor responses may partly occur via activation of some brainstem pathway which in turn facilitates spinal cord Interneuronal activity. However, since electrical stimulation of the pyramidal tract ipsilateral to the caudate nucleus activates the corticospinal fibers in both orthodromic and antidromic directions, facilitation at the cortical level cannot be excluded. Furthermore, all levels of the pyramidal tract are contaminated with non-pyramidal tract flbers. The bulbar pyramidal tract provides the best level 
of study since fiber contamination is not as great as that at other levels of the tract (64). Although only fac1litation by the caudate nucleus upon pyramidal tract induced activity was observed, the level at which facilitation occurred could not be precisely defined. Antidromic stimulation of corticospinal and caudatopedal pathways offer alternate mechanisms by which facilitation of pyramidal tract induced activity can occur.

3. Decorticate Preparation

The results of the present study indicate that in the decorticate preparation only enhancement or no influence upon the pyramidal tract induced increase in Ia afferent activity occurred. Fac1l1tatory loc1 were located throughout the caudate nucleus, but occurred much less frequently as compared to the intact preparation. Simultaneous stimulation of the pyramidal tract and loci within the anterior region of the caudate nucleus did not elicit inhibition of pyramidal tract induced activity, an observation confirmed by Mettler (55). He found that cortical ablation resulted in a deficit of Inhibitory influences from the caudate nucleus upon reflex Induced activity. Mettler concluded the striatum has a pure inhibitory or steadying influence upon cortically Induced activity.

4. Facilitatory Modulation of the Globus Pallidus

Stimulation of some sites with the globus pallidus resulted in facilitation of cortically induced and pyramidal 
tract induced flexor responses in the various preparations used in the present profect. Substantiating evidence for the existance of facilitatory output from the pallidum is provided by recordings of unit activity during task related movements in the monkey (13). Cells within the globus pallidus associated with the particular types of movement were tonically active and Increased their discharge rate prior to the onset of movement. A temporal relationship existed between the increased discharge rate that occurred and the phase of movement. No cessation of discharge rate prior to movement occurred in any of the units studies. That pallidal cells respond prior to the onset of movement further supports the present results that the globus pallidus influences cortically induced flexor responses in a facilitatory manner.

\section{Current spread}

The question of current spread was a consideration in the present investigation. One investigator $(45,46,48,49)$ has attributed all cortical or motor responses excluding contraversive head turning and circling to current spread to the internal capsule rather than stimulation of the caudate nucleus. In the present investigation, positive, negative, and Inactive loci existed side by side in the caudate nucleus. The systematic localization of these loci were consistent in the various experimental approaches, le, location of the locl within the caudate nucleus that inhibited cortically 
Induced responses tended to be localized toward the rostral portion of the caudate nucleus. Such caudate nucleus loci tended to be distributed well within the subcortical structure. In contrast, stimulation of loci within the internal capsule consistently facilieted cortically induced and pyramidal tract induced activity. No inhibitory or inactive loci were located in the internal capsule. Globus pallidus fac1litatory sites were surrounded by 1nactive loc1, an observation which would also tend to demonstrate lack of current spread to the internal capsule.

A sedond consideration Involves corticofugal fibers. One could argue that stimulation of the caudate nucleus could result in selective activation of corticopedal fibers and therefore cortical modulation would be attributed to antidromic stimulation of these fibers. The corticocaudate nucleus profection is composed of very thinly myelinated, fine calibar axons, whereas the efferent fiber poojection is composed of more heavily myelinated and larger axons. The stimulus intensity was adfusted such that 1 t was below that necessary to activate C fibers in the periphery, a threshold level that would correspond to the vast majority of caudatopedal axons. Buchwald and co-workers (4) also noted no antidromic cortical response to medial caudate stimulation. Stimulation, then, of the caudate nucleus would more likely result in excitation of intracaudate cells and/or 
efferent axons.

B. Proposal of Hypothesis for the Level of Integration of Inhibitory Influences

Anatomical evidence demonstrates two possible circuits for basal ganglia influences: (1) the basal ganglia have fiber trajectories to other subcortical structures which in turn project to the spinal level; and (2) the basal ganglia profect to the thalamus which in turn project to cortical areas that are involved in motor functions. In the series of Intact, anesthetized preparations, both facllitatory and Inhibitory loci occurred with respect to cortically induced flexor responses. In contrast, no inhibltory loci and fewer per cent of facilitatory loci were observed with respect to pyramidal tract induced flexor responses in the decorticate preparation. Also, no inhibition of pyramidal tract induced flexor responses occurred in the intact, anesthetized preparation. These observations in $11 \mathrm{ght}$ of known anatomical connections ( 42,61$)$ suggest that: (1) Inhibitory modulation of the caudate nucleus on cortically induced activity occurs at the cortical level; and (2) that some facilitatory modulation also occurs via the cortex.

C. Unanesthetized Preparation

The above hypothesis proposes that most or all inhibitory and some facilitatory induced activity by the caudate nucleus occurs at the cortical level. A series of unanesthet1zed, but 1 mmobllized cats were employed in order to 
to further define the modulation of the basal ganglia upon cortically induced motor activity. The pyramidal tract served as a representative pathway coveying motor influences from the cortex. Direct and indirect waves elicited by electrical stimulation of the cortex were recorded in the pyramidal tract. Zanchett 1 and Brookhart (87) have provided evidence that evoked discharges recorded in the pyramidal tract could serve as a measure of cortical responsiveness. Furthermore, In the present experiments the placement of the cortical and pyramidal tract electrodes was similar for both the anesthetized and unanesthetized preparations. When used as stimulating electrodes in the anesthetized preparation, both the cortical and pyramidal tract electrodes invariabily elicited flexor responses. Therefore, evoked D-I responses in the pyramidal tract in the unanesthetized preparation provides an Indication of cortically induced motor activity; these responses can be modulated by stimulation of basal ganglia structures.

Stimulation of some loci in the caudate nucleus in confuncture with the cortex decreased the cortically induced D-I responses. Inhibitory loc1 tended to be distributed toward the rostral region of the caudate nucleus and was simflar to the distribution anesthetized prepartion. The resulting decrease in the amplitude of the direct and indirect waves recorded in the pyramidal tract would reflect a de- 
crease in descending influences Impinging upon the spinal level. From the present evidence and that of other investigators $(55,57)$, it can be demonstrated that the caudate nucleus exerts some inhibltory influences upon the cortex. Mettler demonstrated that the integrity of the motor cortex was necessary in order for caudate nucleus induced inhibition of pre-existing motor activity to occur. Intracellular cortical studies conducted by Hull and Buchwald $(34,35,36)$ demonstrate that stimulation of the caudate nucleus results In a characteristic membrane hyperpolarization of cortical neurons. Demetrescu and Demetrescu (14) demonstrated the reduction of evoked cortical responses by stimulation of the caudate nucleus. The present investigation extends all of the above observations by demonstrating that stimulation of some caudate nucleus sites inhibits cortical cells whose axons profect in the pyramidal tract. Paradoxically, Hodes and Peacock $(32,56)$ excluded the rostral portion of the globus pallidus and most of the striatum as contributing to any significant extent to central facilitation.

In summary, fac1litatory and inhibitory influences were elicited by high frequency stimulation of the caudate nucleus in the present study. Both facilitatory and inhibltory loci occurred in the same anfmal and these loc1 occurred side by side in the rostral region of this subcortical structure. Facilitatory influences from the caudate nucleus 
tended to modulate cortically induced activity both on a subcortical level and a cortical level. Inhibitory influences of the caudate nucleus modulate induced activity on a cortical level. The descrepancy of a greater number of facilitatory influences than inhibitory influences evoked by the caudate nucleus could be partly a result of the frequency utilized in the preparations. Other researchers (4) utilized a low frequency of stimulation to obtain inhibition from the caudate nucleus whereas high frequency stimulation was employed in the present project. During high frequency stimulation, long duration positive membrane potential shifts tend to occur rather than EPSP-IPSP sequences.

D. Synthesis: Regulatory Influences of the Basal Ganglia From the above description, one can see that the basal ganglia are organized to exert either facilitatory or inhibitory influences on movement during high frequency stimulation of the caudate nucleus. Two possible alternative explanations can be proposed to explain how these influences are manifested at cortical and subcortical levels. One is that there are two separate classes of tonically discharging pallidal cells that are both activated by the caudate nucleus. One group of pallidal cells, when activated by the caudate nucleus, facilitates cortical cells whose axons traverse in the pyramidal tract. This group could also exert facilitation at subcortical levels. The second group of pallidal 
cells also activated by the caudate nucleus would inhibit cortical cells whose axons are in the pyramidal tract. Evidence for this model has been provided by unit activity recordings in which pallidal cells increase discharge rate prior to the onset of movement $(12,13)$.

Evidence opposing this mechanism is the fact that the most common response in pallidal cells due to electrical stimulation of the caudate nucleus is a large amplitude IPSP (52). Furthermore, Zelenskeya (74) demonstrated that stimulation of the caudate nucleus elicited EPSP-IPSP responses in the globus pallidus. He noted that stimulation of the caudate nucleus elicited inhibitory influences in the ventral region of the pallidum. Recent evidence of Buchwald and co-workers (84) further substantiates the above proposal by showing that electrical stimulation of the caudate nucleus evokes EPSP, EPSP-IPSP, and IPSP responses in pallidal neurons. Thus, these studies provide evidence for a bidirectional control of the globus pallidus. The present study further substantiates this control by demonstrating that: (1) stimulation of the cortex facilitated Ia afferent activity and evoked D-I responses within the pyramidal tract; (2) the caudate nucleus facilitated or Inhibited this cortically induced activity; and (3) the globus pallidus only facllitated cortically induced activity. A more parsimonious explanation of caudate nucleus modulation of cortical motor output then is that 
the caudate nucleus has a facilitatory and inhibitory output control of globus pallidus cells but that globus pallidus cells have a predominately or exclusively facilitatory output control upon those cortical cells whose axons profect in the pyramidal tract. Pallidal axons would also excite subcortical neurons which in turn facllitate motor output at the spinal level. Cells within the globus pallidus are spontaneously active. The caudate nucleus, then, facilitate and inhibits this activity within the globus palidus. The latter would in turn modulate cortical activity via the thalamus but only in a facilitatory manner. That a thalamic relay is an intermediate component in this mechanism is supported by anatomical evidence $(61,62)$ as well as electrophysiological data $(30,51)$ that demonstrates that the integrity of the ventralis lateralis is necessary for the production of cortical responses evoked by caudate nucleus stimulation. Figure 19 is a model synthetized from information obtained in the present research and from other studies $(8,30,73)$. According to this model, high frequency stimulation to the caudate nucleus facilitates or inhibits the spontaneous activity of pallidal cells (42). Stimulation of the caudate nucleus would thereby indirectly inhibit or facilitate cortical cells whose axons profect in the pyramidal tract. Basal ganglia influences mediated via subcortical levels facilitate cortically induced and pyramidal 
Figure 19 Synthesis: Regulatory Influences of the Basal Ganglia

$$
\begin{aligned}
& \text { Abbreviations are as follows: } \\
& \text { Cd - caudate nucleus } \\
& \text { CX - cortex } \\
& \text { GP - globus pallidus } \\
& \text { PT - pyramidal tract }
\end{aligned}
$$




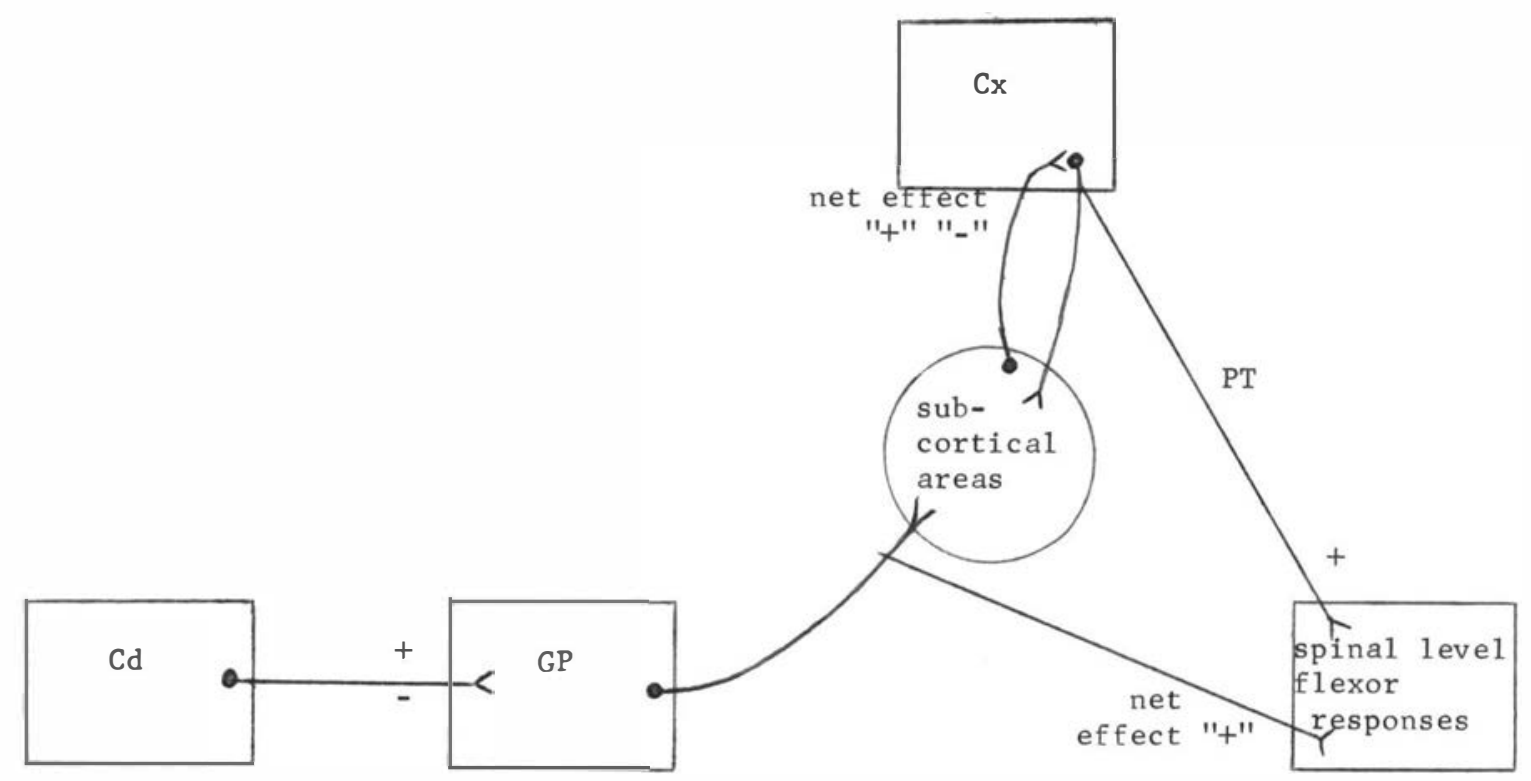


tract activity on a spinal level.

E. Central Regulation of Movement

The cortex was once considred to initiate movement via a corticospinal pathway and some flber pathways which profected to subcortical structures (18). These subcortical structures In turn descend to the spinal level. This concept, then, considered the subcortical structures as the final level In the neuroaxis before the spinal level. Recent proposals developed a hierarchy in which: (1) subcortical structures influence the cortex; and (2) the cortex is considered more closely linked to the spinal level. DeLong $(11,12,13)$ and Thach (81) demonstrated an 1ncrease in unft activity in the putamen, globus pallidus and cerebellum prior to the onset of movement. Porter (66) and Evarts (19) obtained an increase in cortical activity prior to the onset of movement. This cortical activity preceded a decrease in extensor motoneuronal activity which In turn preceded an increase in flexor motoneuronal activity. The latter occurred concomitantly with the onset of movement. Therefore, both the cortico-spinal system and the basal ganglia are concurrently involved not only with tension development of movement but also in the temporal relationship of activation, or even the initiation of movement. Kornhuber (44) hypothesis considers the major function of the basal ganglia as a ramp generator, 1e, Involved in a 
constant velocity of movement. Input to the basal ganglia from foint receptors and the muscle spindle would provide information concerning muscle length and velocity of movement. Dysfunction of the basal ganglia would involve the release of function or deficit of ramp generation. Athetosis, a slow wringing type of movement, is a representative example of basal ganglia defic1t, whereas hemiballism, a rapid, Involuntary movement generally involving the entire extremity would be a demonstration of release of function. According to Kornhuber, the cerebellum would be more involved in the regulation of ballistic movements. However, Delong (11) has provided evidence that the basal ganglia not only function as a ramp generator but may also be involved in ballistic movements. H1s contention was based on a demonstration that units within the putamen respond to fast as well as to slow movements. Movements ellcited from the cortex, then would be regulated by both cerebellar and basal ganglia structures. This 1dea is substantiated by several researchers $(11,81)$ and 1 s consistent with results of the present Investigation.

A consideration of basal ganglia influences upon cortical and pyramidal tract evoked activity by itself does not accurately define the role of the basal ganglia in the central regulation of movement, since this function can be expanded as a system interdependent with behavioral dimensions such as feeding behavior. Sorenson (76), and Wang and Akert 
(84) studied behavioral organization that occurred with lesions of the striatum in the rat and cat, respectively. Sorenson related the degree of feeding behavior to the extent of the striatal lesion. A striatal preparation is one in the cerebral cortex was removed and in some cases varying degrees of the caudate nucleus were removed. A thalamic animal is one in which the thalamus is the highest remaining structure in the functional organization of the central nervous system. Thus, in the thalamic preparation, the striatum is completely removed. Both researchers observed that striatal animals spontaneously ate and groomed themselves whereas the thalamic preparation did not feed or groom. When food was placed in the mouth of a thalamic preparation, the animal would chew but not swallow, thereby indicating that the organization of feeding behavior following eating was also disrupted inthis preparation.

Sorenson postulated that feeding behavior was correlated with the amount of caudate nucleus present. Diencephalic structures have been postulated to be involved in appetitive behavior. The mechanisms facilitated by diencephalic structures involved in feeding behavior include a complex organization of locomotion to find food and the sequence of behavior related to feeding and grooming. These mechanisms are suppressed until the appropriate time for feeding behavior to occur. When feeding behavior is elicited other motivated 
activities need to be suppressed. He proposed the hypothesis the thalamic animal lacks the inhibitory influences from the striatum to suppress other behavioral activities in order that feeding behavior be the only active behavioral activity. As the extent of the caudate lesion is decreased, a greater inhibitory influence over non-feeding behavior is exerted. Therefore, activity is channeled to motivational sequences for feeding.

The basal ganglia may also have a functional role in learned tasks, Buchwald $(2,7,8,30)$ attempted to relate the "Inhibitory" caudate nucleus loop to behavioral observations resulting from caudate nucleus stimulation. During low frequency stimulation, the cat passed from an aroused state to a state of drowsiness and the accuracy of a bar pressing task decreased during this period, whereas the reaction time for the task increased. A novel stimulus presented to the animal would re-initiate the task. High frequency stimulation within the caudate nucleus did not decrease reaction time nor increase performance level in the task related situation. However, if low frequency stimulation applied to the caudate nucleus resulted in cessation of the task, reapplication of high frequency stimulation resulted in initiation of the task. If both low and high frequency stimulation were applied simultaneously to the caudate nucleus the task continued. As previusly described, Delong 
obtalned increases in unit discharge prior to the onset of movement and postulated that the basal ganglia may be involved in the initiation of movement. Therefore, in consideration with the above observations of Buchwald, a high frequency stiumlus mechanism activating the basal ganglia may be involved in the inftiation of movement. The concept for initiation of movement may be further substantiated by a clinical correlation in which the Parkinsonian patient has difficulty in the slow inftiation of movement.

The present research demonstrates that the basal ganglia modulate outputs of both cortical and subcortical motor systems. Thus, the basal ganglia not only recelve inputs from many central nervous system regions but may exert modulating influences on several efferent systems. Furthermore, the basal ganglia are not only involved in the regulation of movement, but are also involved in the regulation of complex motivated behaviors. Although these two functions may operate independently, it seems more $11 k e l y$ that the regulation of motivated behaviors and the modulation of locomotor activity are to an extent subserved by common neural mechanisms within the basal ganglia. 
SUMMARY

Physlological mechanisms underlying basal ganglia have been difficult to assess due to: (1) electrical stimulation and discrete surgical lesions within these structures fall to produce as significant a response as that observed In dysfunction; and (2) the basal ganglia are many synapses removed from sensory input and from lower motoneurons. However, two general mechanisms based on anatomical studies are possible for modulation of motor activity by the basal ganglia. These mechanisms are: (1) modulation of the output of cortical neurons that exert motor influences and (2) modulation of subcortical neurons that exert motor influences.

Differentiation between these two mechanisms was accomplished in the present study by two experimental approaches, both of which employed the conditioning-test paradigm. The first approach was an investigation of basal ganglia modulation (conditioning stimulus) of flexor responses of the anterior tibialis muscle elcited by electrical stimulation of the sensorimotor cortex (test stimulus) and pyramidal tract (test stimulus). These investigations were carried out in the intact and in decorticate cats. The anterfor tibialis muscle is activated during the first phase of movement and was therefore used in this study since a characteristic of some basal ganglia dysfunctions 
involve a show onset or initiation of movement.

The second approach was an analysis of modulation of cortically induced pyramidal tract responses by conditioning shock trains delivered to various loci within the basal ganglia. Both approaches were designed to determine whether inhibitory and facilitatory motor influences of the basal ganglia occurred at a cortical or subcortical level.

Simultaneous pairing of the caudate nucleus and cortex evoked either an enhancement, reduction or no alteration of the cortically induced increase in flexor responses (measured by Ia afferent activity, EMG, myogram) whereas no inhibitory influences occurred from caudate nucleus stimulation upon pyramidal tract induced flexor responses in either the intact or decorticate preparation. Inhibitory loci were distributed toward the rostral portion of the caudate nucleus, whereas facilitatory loci were distributed throughout; and this distribution was statistically significant (Chi Square; $p<0.01$ ). Only enhancement or no influence upon cortical induced or pyramidal tract induced responses were obtained by conditioning stimuli to the globus pal11dus.

In the unanesthetized, but immobilized cat, trains of shocks delivered to the caudate nucleus enhanced, reduced or had no influence upon the cortically evoked direct and indirect responses recorded in the bulbar pyramidal tract. 
Distribution of facilitatory and inhibitory loci were organfzed in a simflar fashion as in the anesthetized preparation. Facilitatory and inhibitory loci existed side by side In the rostral portion of the caudate nucleus and inhibitory loc1 occurred with significantly greater frequency in rostral as opposed to the caudal half of the caudate nucleus ( $C h 1$ Square, $p<0.01)$. Fac1l1tatory loc1 were distributed throughout the structure.

From these observations, a model was proposed in which the output of the caudate nucleus exerts a bidirectional control: the caudate nucleus exerts both facilitatory or Inhibitory modulation of the tonically active globus pallidus cells. The latter in turn predominately or exclusively facilitates the pyramidal tract output as well as the output of subcortical structures; both effects facilitate motor responses at the spinal level. 


\section{REFERENCES}

1. Bloom, F. E., E. Costa, G. C. Salmo1rgh1. Anesthesia and the Responsiveness of Individual Neurons of the Caudate Nucleus of the Cat to Acetylocholine, Norepinephrine and Dopamine Administered by Microelectrophores1s. J. Phram and Exp. Ther. $150: 243-252,1965$.

2. Buchwald, N. A., G. Heuser, E. J. Wyers, C. W. Lauprecht, The "Caudate-Spindle" III. Inhibition by High Frequency Stimulation of Subcortical Structures. Electroencepha1. C11n. Neurophys1ol. 13:525-530, 1961 .

3. Buchwald, N. A., C. D. Hull, M. S. Levine, D. R. G. Fuller. Striatal Inputs to Pallidal Neurons. (abs). Soclety for Neurosclence Bulletin. p. 186 (to be presented Nov. 1973).

4. Buchwald, N. W., C. D. Hull, L. M. Vernon, G. A. Bernard1. Physlological and Psychological Aspects of Basal Ganglia Functions. G. Crane and R. Gardner, Jr. (eds.), Psychotrophic Drugs and Dysfunctions of the Basal Ganglia, Public Health Services Publication \#1938, U. S. Printing Office, Washington, D.C., pp. 82-91, 1969 .

5. Buchwald, N. A., C. D. Hull, M. C. Trachtenberg. Concomitant Behavorlal and Neuronal Inhibltion and Disinhibition in Response to Subcortical Stimulation. Expl. Br. Res. $4: 58-72,1967$.

6. Buchwald, N. A., D. D. Price, L. Vernon, C. D. Hull. Caudate Intracellular Responses to Thalamic and Cortical Inputs. Expl. Neurol. 38:311-323, 1973.

7. Buchwald, N. A., E. J. Wyers, C. W. Lauprecht, G. Heuser. The "Caudate-Spindle" IV. A Behavioral Index of Caudate-Induced Inhibition, Electroencephal. C11n. Neurophys1o1. 13:531-537, 1961.

8. Buchwald, N. W., E. J. Wyers, T. Okuma, G. Heuser. The "Caudate-Spindle" I. Electrophyslological Properties. Electroencephal. Clin. Neurophysiol. $13: 509-518,1961$. 
9. Bucy, Paul C. The Neural Mechanisms of Athetosis and Tremor. J. Neuropath. Exp. Neurol. 1:224-239, 1942.

10. Davis, G. D. Caudate Lesions and Spontaneous Locomotion In the Monkey. Neurol. 8: 135-139,1958.

11. Delong, M. Putamen: Activity of Single Units During Slow and Rapid Arm Movements. Science 179:1240-1242, 1973 .

12. Delong, M. Activity of Basal Ganglia Neurons During Movement. Br. Res. 30:127-135 1972.

13. DeLong, M. Activity of Pallidal Neurons During Movement. J. Neurophys1ol. 34:414-427, 1971 .

14. Demestrescu, M., M. Demetrescu. The Inhibitory Action of the Caudate Nucleus in Cortical Primary Recelving Areas in the Cat. Electroenceph. Clin. Neurophys1o1. 14:37-52, 1962 .

15. Demetrescu, M., M. Demetrescu, G. Iosif. The Tonic Control of Cortical Responsiveness by Inhibitory and Facilitatory Diffuse Influences. Electroenceph. C11n. Neurophysiol. 18:25-35, 1965 .

16. Dusser de Barenne, J., W. S. McCulloch. Sensorimotor Cortex, Nucleus Caudatus and Thalamus Opticus. J. Nurophys1ol. 1:364-377, 1938 .

17. Engberg, I., A. Lundberg. An Electromyographic Analysis of Muscular Activity in the Hindlimb of the Cat during Unrestrained Locomotion. Acta. Physiol. Scand. 75:614-630, 1969 .

18. Evarts, E., et al. Central Control of Movement. Neurosciences Research Bulletin 9: 1-170, 1971 .

19. Evarts, E. V. Contrasts between Activity of Precentral and Postcentral Neurons of Cerebral Cortex during Movement in the Monkey. Br. Res. 40:25-31, 1972 .

20. Falch, B., N. A. Hillarp, G. Thieme, A. Torp.

Fluorescence of Catecholamines and Related Compounds Condensed with Formaldehyde. J. Histochem. Cytochem. 10:348-354, 1962 .

21. Felz, P., J. S. Mackenz1e. Properties of Caudate Unitary Responses to Repetitive Nigral Stimulation. Br. Res. $13: 612-616,1969$. 
22. Fernstrom, R. A Durable N1ssl Stain for Frozen and Paraffin Sections. Stain Tech. 33:175-176, 1968 .

23. Forman, D., J. W. Ward. Responses to Electrical Stimulation of Caudate Nucleus in Cats in Chronic Experiments. J . Neurophys1o1. 20:230-244, 1957 .

24. Freeman, G. L., L. Kranso. Inhibitory Functions of the Corpus Striatum. Arch. Neurol. Psych. 44: $323-327,1940$.

25. Goldring, S., L. U. Anthony, P. E. Stohr, J. L. O'Leary, "Caudate-Induced" Cortical Potentials: Comparison Between Monkey and Cat. Science 139:772, 1963.

26. Granit, R., B. R. Kaada. Influences of Stimulation of Central Nervous Structures on Muscle Spindles in Cat. Acta Phys1ol. Scand. 27:130-160, 1953.

27. Gran1t, R., Van Der Meulen. The Pause during Contration in the Discharge of the Spindle Afferents from Primary End Organs in Cat Extensor Muscles. Acta. Physiol. Scand. 55:231-244, 1962.

28. Guzman, Caros., M. V. Alcaraz, A. Fernandez. Rap 1d Procedure to Localize Electrodes in Experimental Neurophys1ol. Bol. Inst. Estudios Med. B1ol. 16: $29-31,1958$.

29. Harman, P. J., M. B. Carpenter. Volumetric Comparisons of the Basal Ganglia of Various Primates Including Man. J. Comp. Nurol. 93:125-138, 1950.

30. Heuser, G., N. A. Buchwald, E. J. Wyers. The "CaudateSpindle" II. Facilitatory and Inhibitory CaudateCortical Pathways. Electroenceph. Clin. Neurophys1o1. 13:519-524, 1961 .

31. Hodes, R. Electrocortical Synchronization Resulting from Reduced Proprioceptive Drive Caused by Neuromuscular Blocking Agents. Electroenceph. Clin. Neurophys1o1. 14:220-232, 1962 .

32. Hodes, R., S. M. Peacock, Jr., R. G. Heath. Influences of the Forebrain on Somato-Motor Activity I.

Inhibition. J. Comp. Neurol. 94:381-408, 1951 . 
33. Horvath, F. E., S. Soltysik, N. A. Buchwald. Spindles Elicited by Stimulation of the Caudate Nucleus and Internal Capsule. Electroenceph. Clin. Neurophys 1ol. $17: 670-676,1964$.

34. Hul1, C. D., G. Bernard1, N. A. Buchwald. Intracellular Responses of Caudate Neurons to Brain Stem St1mulation. Br. Res. 22:163-179, 1970 .

35. Hul1, D., G. Bernard1, D. D. Price, N. A. Buchwald. Intracellular Responses of Caudate Neurons to Temporally and Spatially Combined St 1mul1. Exp. Neurol. 38:324-336, 1973 .

36. Hull, C. D., N. A. Buchwald, L. M. Vernon. Intracellular Responses in Caudate and Cortical Neurons. G. Crane and R. Gradner, Jr. (eds) Psychotroph1c Drugs and Dysfunctions of the Basal Ganglia. Publ1c Health Service Publication \#1938, U. S. Government Printing Office Washington, D.C., p p. $92-97,1969$.

37. Hull, C. H., N. A. Buchwald, J. Vieth. Cortical Intraceliular Analysis of Responses to Inhibitory and Disinhibitory Stimul1. Br. Res. 6:12-21, 1967.

38. Kemp, J. M., T. P. S. Powe1l. The Structure of the Caudate Nucleus of the Cat: Light and Electron Microscopy. Phil. Trans. R. Soc. Lond. Series B. 262:383-401, 1971 .

39. Kemp, J. M., T. P. S. Powell. The Synapt1c Organization of the Caudate Nucleus. Ph1l. Trans. R. Soc. Lond. Ser. B. 262:403-412, 1971 .

40. Kemp. J.M., T. P. S. Powell. The Site of Termination of Afferent Fibers in the Caudate Nucleus. Phil. Trans. Roy. Soc. Lond. Ser. B. 262:413-427, 1971 .

41. Kemp. J. M. T. P. S. Powell. The Termination of Fibers from the Cerebral Cortex and Thalamus Upon Dendritic Spines in the Caudate Nucleus: A Study with the Golg1 Method. Ph11. Trans. Roy. Soc. Long. Ser. B. 262:429-439, 1971 .

42. Kemp, J.M., T. P. S. Powell. The Connexions of the Striatum and Globus Pallidus: Synthesis and Speculation. Phil. Trans. R. Soc. Lond. Ser. B. 262: $441^{-} 457,1971$. 
43. Kennard, M. A. Experimental Analysis of the Functions of the Basal Ganglia in Monkeys and Chimpanzees

J. Neurophys1ol. 7:127-148, 1944 .

44. Kornhuber, H. H. Motor Functions of Cerebellum and Basal Ganglia: The Cerebellocortical Saccadic (Ballistic) Clock, the Cerebellonuclear Hold Regulator, and the Basal Ganglia Ramp (Voluntary Speed Smooth Movement) Generator. Kybernetik 8: $157-162,1971$.

45. Laursen, A. M. Caudate Nucleus and Electrocortical Activation in Cats. Acta Physiol. Scand. 53: $233-238,1961$.

46. Laursen, A. M. Corpus Striatum. Acta Physiol. Scand. 59: suppl. 211,1963 .

47. Laursen, A. M. Electrical Signs of the Relation between Caudate Nucleus and Cerebral Cortex in Cats. Acta Phys1ol. Scand. 53:218-232, 1961.

48. Laursen, A. M., Inhibition Evoked from the Region of the Caudate Nucleus in Cats. Acta Physiol. Scand. 54: $185-190,1-62$.

49. Laursen, A. M. Movements Evoked from the Region of the Caudate Nucleus in Cats. Acta Physiol. Scand. 54: $175-184,1962$.

50. Liles, S. L., G. D. Davis Interrelation of Caudate Nucleus and Thalamus in Alternation of Cortically Induced Movement. J. Neurophysiol. 32:564-573, 1969.

51. Liles, S. L., G. D. Davis. Electrocortical Effects of Caudate Stimulations which Alter Cortically

Induced Movement. J. Neurophys1ol. 32:574-582, 1969.

52. Mallian1, A., D. P. Purpura. Intracellular Studies of the Corpus Striatum II. Patterns of Synaptic Activities in Lenticular and Entopenduncular Neurons. Br. Res. 6: 341-354, 1967 .

53. Matthews, B. H. C. Nerve Endings In Mammalian Muscle. J. Phys1o1. 78:1-53, 1933 .

54. Mettler, F. A. Striatally Induced Obstinate Progression in Primates. Fed. Proc. 32:339 (abs) 1973. 
55. Mettler, F. A., H. W. Ades, E. L1pman, F. Culler. The Extrapyramidal System, An Experimental Demonstration of Function. Arch of Neurol. Psych. 41:984-995, 1939 .

56. Mettler, F. A., H. Ades, E. L1pman, F. Culler. The Physiology of the Corpus Striatum. Am. J. Physiol. 126: P 584-P585, 1939 .

57. Mettler, F. A., C. C. Mettler. The Effects of Striatal Infury. Brain 65:242-255, 1942 .

58. Mettler, F. A., C. C. Mettler. Extrapyramidal Inhibition of Cortically Induced Movement. Am. J. Phys1ol. 129: P 243,1940 .

59. Mettler, F. A., C. C. Mettler. Role of the Neostriatum. Am. J. Physiol. 133:594-601, 1941.

60. Morgan, L. 0. The Corpus Striatum. Arch. Neurol. Psych. 18:495-549, 1927 .

61. Nauta, W. J. H., W. R. Mehler. Profections of the Lentiform Nucleus in the Monkey. Br. Res. 1 : $3-42,1966$.

62. Nauta, W. J. H., W. R. Mehler. Some Efferent Connections of the Lentiform Nucleus in Monkey and Cat. Anat. Rec. 139:260, 1961 .

63. Noda, H., S. Manohar, W. R. Adey. Responses of Cat Pallidal Neurons to Cortical and Subcortical Stimuli. Exp. Neurol. 20:585-610, 1968 .

64. Patton, Harry D., Vahe E. Amassian. The Pyramidal Tract: Its Exc1tation and Functions. Chap. XXXIV, Pp. 837861. John Field, H. W. Magoun, V. E. Hall. Handbook of Physlology, Section I: Neurophyslology, Volume II. American Physiological Society, Washington, D.C., 1960 .

65. Peacock, S. M., Jr., R. Hodes. Influence of the Forebrain on Somato-Motor Activity II. Facilitation. J. Comp. Neurol. 94:409-426, 1951 .

66. Porter, R. Relationship of the Discharges of Cortical Neurons to Movement in Free-to-Move Monkeys. Br. Res. $40: 39-43,1972$. 
67. Purpura, Domin1ck P., Alberto Malian1. Intracellular

Studies of the Corpus Striatum. I. Synaptic

Potentials and Discharge Characteristics of the

Caudate Neurons Activated by Thalamic Stimulation.

Br. Res. $\underline{6}: 325-340,1967$.

68. Rocha-Miranda, C. D. Single Unit Analysis of CortexCaudate Connections. Electroenceph. Cl1n.

Neurophysio1. 19:237-247, 1965 .

69. Sasak1, K., A. Nam1kawa, M. Matsunaga. Effects of Stimulation of the Pyramidal Tract and Striate Body upon Spinal Motoneurons. Jap. J .

Physiol. 10:403-413, 1960.

70. Schlag, J. Reactions and Interactions to Stimulation of the Motor Cortex of the Cat. J. Neurophysiol. 29: $44-71,1966$.

71. Sedgwick, E. M., T. D. W1111ams. The Response of Single Units in the Caudate Nucleus to Peripheral Stimulation. J. Physiol. 189:281-288, 1967 .

72. Segundo, J., X. Machne. Unitary Responses to Afferent Volleys in Lenticular Nucleus and Claustrum. J. Neurophys1o1. 19: 325-339, 1956 .

73. Segundo, J. P., E. F. Migl1aro, J. A. Rolg. Effect of Striatum and Claustral Stimulation upon Spinal Reflex and Strychnine Activity. J. Neurophysiol. 21:391-399, 1958 .

74. Shimazu, Hirosh1, T. Hongo, K. Kubota. Two Types of Central Influences on Gamma Motor System. J. Neurophys1ol. 25:309-323, 1962 .

75. Snider, Ray, W. T. Nieman. A Stereotaxic Atlas of the Cat Brain. The University of Chicago Press, Chicago. 1961 .

76. Sorenson, C. A., G. D. Ellison. Striatal organization of Feeding Behavior in the Decorticate Rat. Expl. Neurol. 28:162-174, 1970 .

77. Sterlade, M. Ascending Control of Motor Cortex Responsiveness. Electroenceph. Clin. Neurophysiol. $26: 25-40$, 1969 .

78. Szabo, J. Topical Distribution of the Striatal Efferents in the Monkey. Exp. Neurol. 5:21-36, 1962. 
79. Szabo, J. Projections from the Tall of the Caudate Nucleus. Anat. Rec. 160:437, 1968 .

80. Szabo, J. Topical Distribution of the Striatal Efferents in the Monkey. Exp. Neurol. ㅁ:21-36, 1962 .

81. Thach, W. Cerebellar Output: Properties, Uses and Synthesis. Br. Res. 40:89-97, 1972 .

82. Villablanca, J. R., J. Marcus. Effects of Bilateral, Simultaneous Abiation of the Caudate Nuclei in Cats. Fed. Proc. 32:339 (abs), 1973 .

83. Voneida, T. J. An Experimental Study of the Course and Destination of Fibers Arising in the Head of the Caudate Nucleus in the Cat and Monkey. J. Comp. Neurol. 115:75-82, 1960 .

84. Wang, G. H., K. Akert. Behavior and Reflexes of Chronic Striatal Cats. Arch. Ital. B1ol. $\underline{100}: 48-85,1962$.

85. Webster, K. E. The Cortico-Striatal Profection in the Cat. J. Anat. (Lond.) 99:329-337, 1965 .

86. Wilson, S. A. K. An Experimental Research into the Anatomy and Physlology of the Corpus Striatum. Brain. $36: 427-492,1914$.

87. Zanchett1, Alberto, J. M. Brookhart. Measurements of Electrical Responsiveness of Cortico-Spinal Efferents In Cat and Monkey. J. Neurophys1ol. 18:288-298, 1955 .

88. Zelenskaya, V. A. Effect of Stimulation of the Caudate Nucleus on Activity of Neurons of the Globus Pallidus. Neurophys1o1. 1:154-159,1969. 